\title{
Ultra Wideband Antennas for High Pulsed Power Applications
}

\author{
Baptiste Cadilhon ${ }^{1}$, Bruno Cassany ${ }^{1}$, Patrick Modin' ${ }^{1}$ \\ Jean-Christophe Diot $^{2}$, Valérie Bertrand ${ }^{3}$ \\ and Laurent Pécastaing 4 \\ ${ }^{1} C E A$, avenue des Sablières, Le Barp, \\ ${ }^{2} \mathrm{CEA}$, Gramat, \\ ${ }^{3}$ CISTEME, ESTER Technopole, Limoges, \\ ${ }^{4}$ LGE, SIAME Laboratory, Pau University, Pau,
}

France

\section{Introduction}

\subsection{UWB antennas in the field of high pulsed power}

For the last few years, the generation of high-power electromagnetic waves has been one of the major applications of high pulsed power (HPP). It has aroused great interest in the scientific community since it is at the origin of several technological advances. Several kinds of high power radiation sources have been created. There currently appears to be a strong inclination towards compact and autonomous sources of high power microwaves (HPM) (Cadilhon et al., 2010; Pécastaing et al., 2009).

The systems discussed here always consist of an electrical high pulsed power generator combined with an antenna. The HPP generator consists of a primary energy source, a power-amplification system and a pulse forming stage. It sends the energy to a suitable antenna. When this radiating element has good electromagnetic characteristics over a wide band of frequency and high dielectric strength, it is possible to generate high power electromagnetic waves in the form of pulses. The frequency band of the wave that is radiated can cover a very broad spectrum of over one decade in frequency. In this case, the technique is of undoubted interest for a wide variety of civil and military applications. Such applications can include, for example, ultra-wideband (UWB) pulse radars to detect buried mines or to rescue buried people, the production of nuclear electromagnetic pulse (NEMP) simulators for electromagnetic compatibility and vulnerability tests on electronic and IT equipment, and UWB communications systems and electromagnetic jamming, the principle of which consists of focusing high-power electromagnetic waves on an identified target to compromise the target's mission by disrupting or destroying its electronic components.

Over the years, the evolution of the R\&D program for the development of HPM sources has evidenced the technological difficulties intrinsic to each elementary unit and to each of the physical parameters considered. Depending on the wave form chosen, there is in fact a very wide range of possibilities for the generation of microwave power. The only real question is 
not "what power can be reached" but rather what power with what repetition rate, with what duration of transmission, with what width of spectrum and with what agility?

Putting each of these parameters on the same level in isolation is meaningless. On the other hand, ranking the impact of each parameter on the opportunity of developing a system makes it possible to outline the avenues of research.

The impact of the antenna unit is a major factor in the sizing of this so-called "system'". In fact, the limitations in terms of transmission power of the existing devices restrict the possibilities of the system. Moreover, the impact of the radiation lobes on the system itself or on the operators is a further limitation to the powers that can actually be reached.

The technological progress achieved on this elementary unit is an immediate point of entry for the sizing of the systems, on a par with other parameters such as the repetition frequency or the duration of operation with impact the energy storage and power amplification means.

\subsection{Brief recapitulation of the state-of-the art in high power UWB antennas}

The classic broad-band antennas available are used in the harmonic mode and do not offer the characteristics expected for experimentations in the transient domain. To be usable, the antennas have to be sufficiently broad band in order to cover the ultra short pulse spectrum generated. The first step is the choice of type of antenna matching the application.

There is a great variety of antennas that can be used for UWB applications, requiring some optimization to meet the requirements, including:

- frequency independent antennas,

- aperture antennas,

- reflector antennas,

- travelling wave antennas.

For most UWB applications, the radiating elements are specifically designed as a part of the complete system for the project in question. We are looking here for an antenna with good directivity, a broad band (to be compatible with the frequency spectrum of the pulse to radiate) and capable of withstanding high voltages (over a several dozen kilovolts). The criterion of dispersion (i.e. the spreading effect of the pulse resulting from a shifting phase center of the antenna) can be an important parameter depending on the application (as in UWB radar or measurement applications). Compactness and integration constraints are becoming increasingly topical and must be taken into account from the outset of the antenna design.

\subsubsection{Frequency independent antennas}

\subsubsection{Log-periodic antennas}

Log-periodic antennas consist of several elementary dipoles mounted in parallel on a two strand armature such that two consecutive dipoles are in phase opposition when the antenna is powered. Each dipole radiates independently with maximum efficacy when its length corresponds to the half wavelength of the power frequency. The low frequency is thus determined by the size of the largest dipole and the high frequency by the size of the smallest dipole.

The antennas available off the shelf generally present an input impedance of $50 \Omega$ over a relatively wide frequency band (approximately one decade). The effective structures in low 
frequency are naturally cumbersome (a low frequency of $200 \mathrm{MHz}$ corresponds to a dipole $75 \mathrm{~cm}$ long). Certain devices combine a biconical antenna with this structure for a trade-off between bulk and bandwidth. The classic structure withstands power levels of no more than few kilowatts for a gain of around $6 \mathrm{~dB}$ over one decade. A major modification of the structure must therefore be envisaged in order to radiate high powers.

\subsubsection{Monopole and dipole}

Outside of their resonance ranges, monopoles and dipoles can be seen as elementary UWB structures. Their gain levels are, however, extremely poor, their radiation patterns are not directional and their input impedances are generally high.

\subsubsection{Horn antennas}

TEM horns are also frequently used for the radiation of ultra short pulse. They have a pyramidal flared or conical shape. In the high frequencies of their use spectrum they are powered more often than not by a wave guide. For the lowest frequencies, the power system generally consists of a coaxial cable ending in a quarter wave strand. That makes it difficult to send high level and especially repetitive signals. This type of wide band antenna is not suitable for operational in a transient regime. Each spectral component is transmitted from a phase center which moves inside thus causing a spread of the signal transmitted. Moreover, performance at low frequencies $(<1 \mathrm{GHz})$ can only be obtained within very large structures. They are very often equipped with a polyethylene lens positioned at the opening of the horn (figure 1) which provides a flat wave at the exit from the antenna, thus reducing spatial scattering. Depending of the level of performance required, however, the lens rapidly becomes cumbersome and considerably increases the size and weight of the antenna as whole.

Addition of a pair of arches the shape of which is exponential to the structure of the horn gives a ridged horn. This modification makes it possible to widen the operational band while keeping within relatively modest dimensions. The problems of high voltage power still remain, however, especially if a balun has to be used to adapt the input impedance of the radiating element (Bigelow et al., 2004).

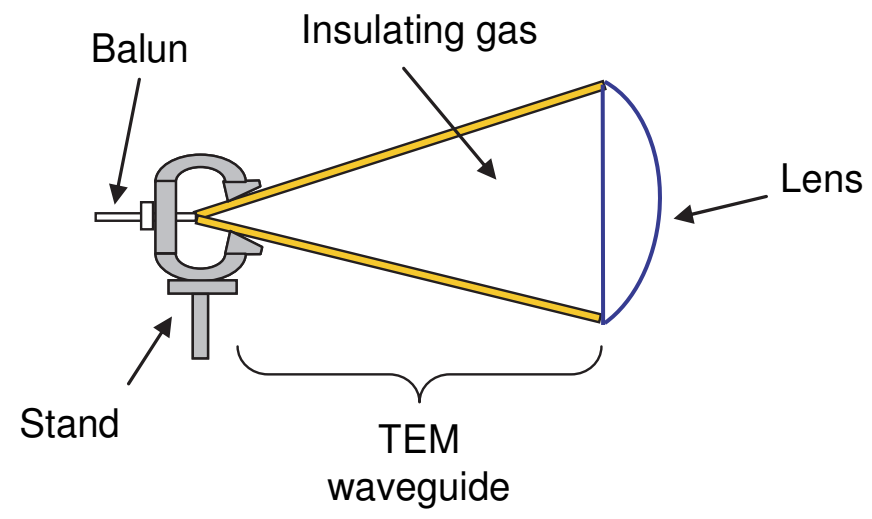

Fig. 1. Schematic cut-away of a TEM horn 
Their combination with a parabolic reflector with the right specifications is easier to install.

\subsubsection{Reflector antennas}

The combination of a parabolic reflector with a UWB source of radiation (typically a horn) makes it possible to reach directivities much greater than those of the antennas presented before.

The radiation source, positioned at the focal point of the reflector (or offset in certain cases) must be adjusted so as not to upset the radiation patterns of the transmission as a whole.
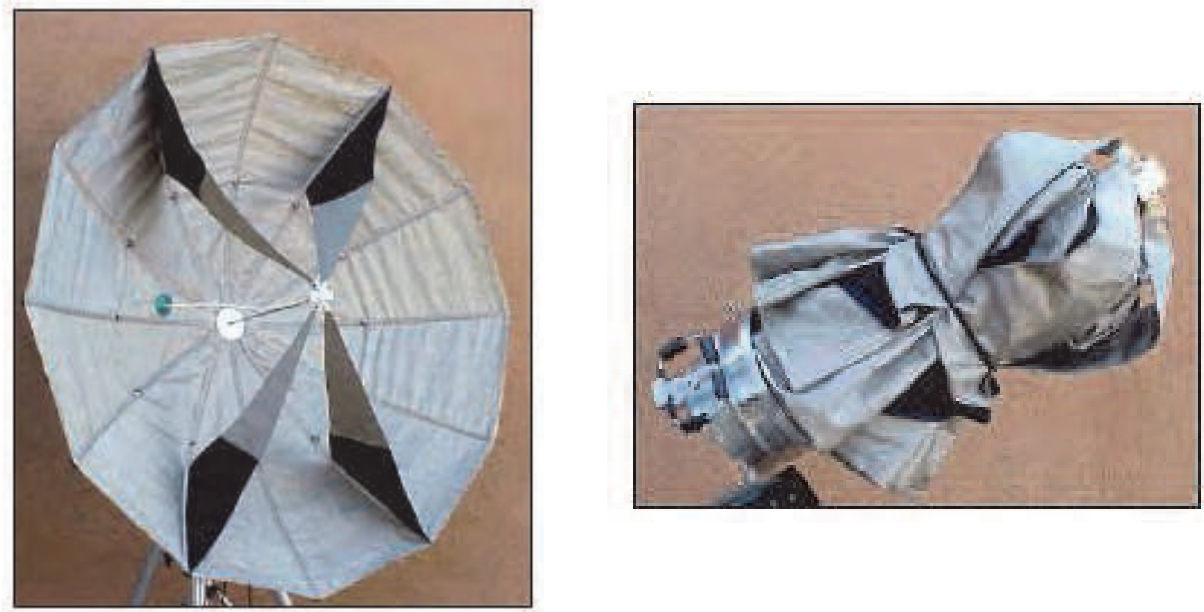

Fig. 2. U-CIRA1 antenna developed by Farr Research (USA)

The Farr Research company excels in this field. The U-CIRA1 antenna shown in Figure 2 (Farr, 2004) is a derivative of the IRA model (Baum \& Farr, 1993), developed by C. Baum. It operates in the $250 \mathrm{MHz}-12 \mathrm{GHz}$ range and presents a relatively constant gain of round $20 \mathrm{~dB}$ as from $2 \mathrm{GHz}$. Its extremely small size (a diameter of $1.42 \mathrm{~m}$ once deployed) makes it one of the best performance antennas in its class.

\subsubsection{Travelling wave antennas}

These antennas are characterized by their specific mode of operation. The radiation element must be extremely large given the wavelength of the signal to be transmitted so that when an excitation current is propagated along the metal structure it is totally radiated before reaching the end. This excludes any phenomenon of resonance or standing waves. In practice, this antenna is difficult to make because the structural dimensions remain in the order of the greatest wavelength to be transmitted. There are various designs aimed at reducing the unwanted reflections at the end and the resulting oscillations. The adaptation of these antennas on $50 \Omega$ is easy over a wide frequency band and effective directional structures can be made. These aerials are the most widely used in impulse UWB applications.

\subsubsection{Biconical antennas, discone and conical skirt monopole}

When they are large enough, these antennas can also be included in the family of travelling wave antennas. The biconical antenna consists of two cones facing each other by their 
summits (or by their bases in the case of the discone). The cones can be made from rolled sheet metal or a set of metal rods. Power is injected at the summit of the cones. The cone corresponds to a biconical half-antenna placed on a ground plane.

The frequency domain of these antennas ranges from $300 \mathrm{MHz}$ to $18 \mathrm{GHz}$. Their adaptation on $50 \Omega$ is obtained by adjusting the half-angle at the summit of the cone(s). The high cut-off frequency is determined essentially by the quality of the electrical continuity between the power line and the summit of the cable. These antennas are very poorly directional and therefore have low gains of less than $4 \mathrm{~dB}$. Their radiation pattern is very similar to that of the dipoles. These aerials are omnidirectional in the $\mathrm{H}$ plane (rectilinear polarization).

\subsubsection{Specially designed antennas}

Several travelling wave antennas can be found in the literature, each designed for a very specific project. The High Current Electronics Institute - HCEI - in Tomsk in Russia has developed an antenna (Koshelev et al., 2001; Efremov et al., 2006; Koshelev et al., 2006) which combines several radiating elements (figure 3): an electric monopole 1, two magnetic dipoles, 5 and 7 and a TEM horn, 6 . The size of the loop, 5, is adjustable by the plate, 4 . This antenna can be assimilated with a travelling wave antenna to which a magnetic loop has been added making it possible to increase the width of the spectrum in the low frequencies.
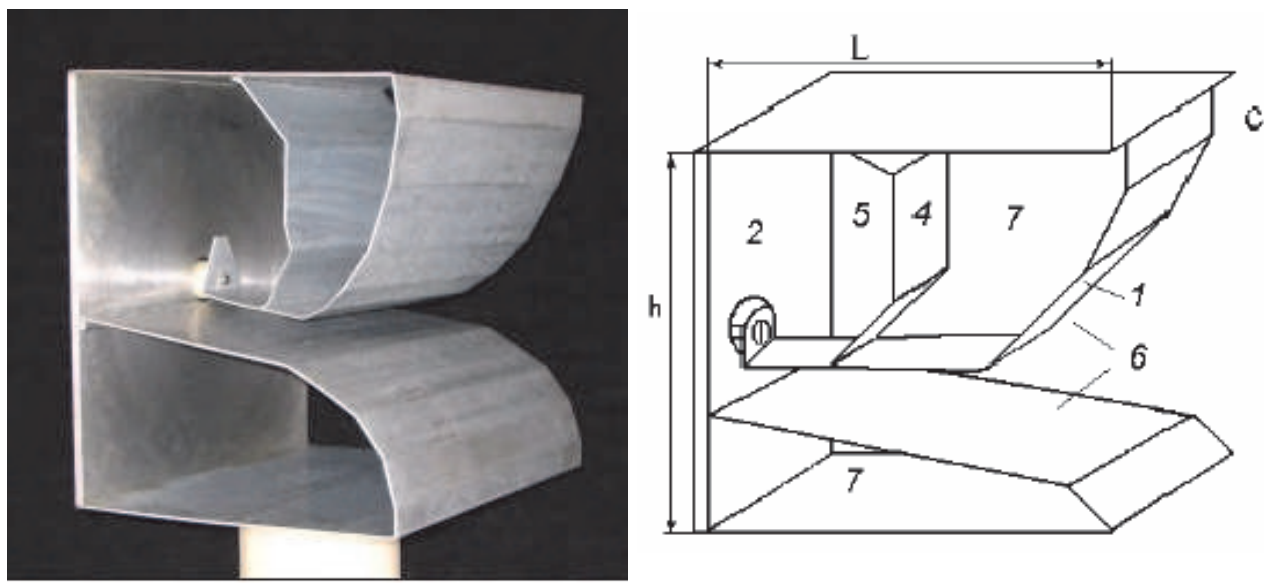

Fig. 3. Combined antenna developed by HCEI $(\mathrm{L}=385 \mathrm{~mm} ; \mathrm{h}=450 \mathrm{~mm})$

Maintained in an atmosphere of SF6, the aerial is capable of withstanding bipolar voltage peak to peak amplitudes of $460 \mathrm{kV}$ for a few nanoseconds $(\tau)$. The length of the antenna, $\mathrm{L}$, is defined by the maximum pulse width to be radiated: $L \approx \tau \cdot c / 2$ (where $c$ is the speed of light). The TOS of the antenna is under 3 in the $200 \mathrm{MHz}-1.5 \mathrm{GHz}$ bandwidth. The gain achieved in the axis is constant between 6 and $8 \mathrm{~dB}$ for a field radiated in vertical rectilinear polarization.

Over the last few years in France, the RUGBI project (the French acronym for "Instantaneous Ultra Wideband Radar") (Diot, 2006) has resulted in the construction of two travelling wave antennas. The aim of this project, pursued by the XLIM laboratory of Limoges University, was to design and produce a multi-source pulsed UWB radar system 
demonstrator based on the use of optoelectronic switches to extend the limits of pulsed UWB radars in terms of range, resolution and acquisition. The antennas developed in the project are based on the Vivaldi type profile, the Valentine antenna (Diot et al., 2007) being used for the construction of the transmission array and the Libellule antenna (Delmote et al., 2004) being used for the reception of the UWB radar signals formed.

These two antennas (figure 4) are made according to the same principle but their geometry is different. The low frequency pulse components propagated on the strands are radiated at the point of the greatest opening of the antenna whereas the high frequency components are transmitted at its entrance. These antennas therefore present a slight distortion of the signal. For the frequencies between $500 \mathrm{MHz}$ and $3 \mathrm{GHz}$, the gain of the Valentine antenna is relatively constant around $10 \mathrm{~dB}$ with $12 \mathrm{~dB}$ between $500 \mathrm{MHz}$ and $4 \mathrm{GHz}$ for the Libellule antenna.

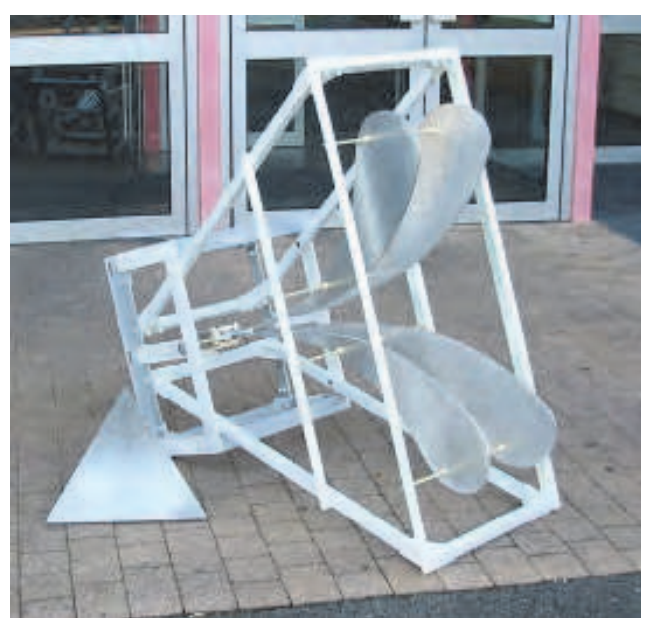

a- Libellule antenna

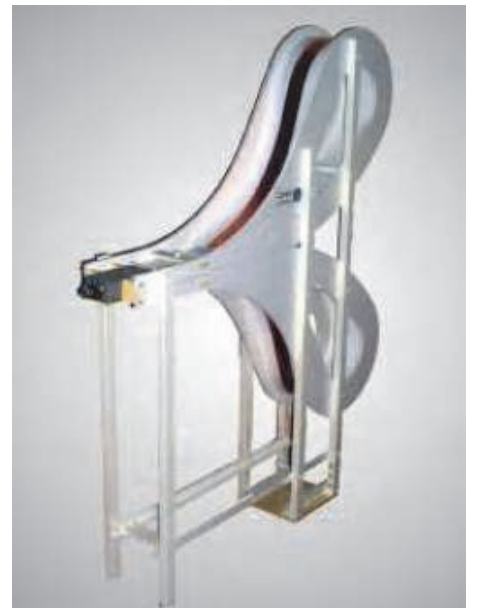

b- Valentine antenna

Fig. 4. Travelling wave antennas developed by XLIM

\subsection{Basic principles}

Within the complete device, the antenna ensures the transmission of energy between the pulsed source and the free space in which it will be propagated. Depending on the quality of the radiating elements, the transmission will be made with varying input losses, the directivity of the radiation and the deformation of the pulse transmitted will both vary.

The design of very wide band antennas in the pulsed regime is more difficult than in the narrow band for many reasons related to the laws of electromagnetism. All transmission antennas are characterized by their transfer function on transmission.

This transfer function $H_{T}$ links the electric field of the wave $E(r, t)$ to the complex amplitude of the incident wave $V_{i}$ on the antenna input port by the relationship of temporal convolution (1):

$$
E(r, t)=\frac{1}{r} \sqrt{\frac{\eta_{0}}{4 \pi}}\left[H_{T}(t) \otimes \delta(t) \otimes V_{i}(t)\right]
$$


where $\eta_{0}$ represent the characteristic impedance of the free space, $r$ the distance as from the center of the phase on which the field $E$ is measured and $\delta(t)$ is the Dirac pulse. This evidences that the temporal shape of the pulse transmitted results from the convolution of the excitation pulse and from pulse response of the antenna. If the latter is not a pure Dirac, it can be seen that the antenna distorts the pulse.

Moreover, within the transmission device, the antenna can be seen generally to be a kind of end dipole which must absorb all the incident energy ( $V_{i}$ wave) to radiate it. That implies that the reflected wave $V_{r}$ must be negligible. The reflection coefficient $S_{11}$ describes the impedance adaptation by linking $V_{i}$ and $V_{r}$ and the impedance of the antenna $Z_{A}$ and to the impedance of the excitation source $Z_{G}$ by (2):

$$
S_{11}=20 \cdot \log \left(\frac{V_{r}}{V_{i}}\right)=20 \cdot \log \left(\frac{Z_{A}-Z_{G}}{Z_{A}+Z_{G}}\right)
$$

It can therefore be seen that total absorption of the excitation wave implies wideband impedance matching, which is a naturally difficult problem. The usual frequency dependency of the behavior of antennas tends to make them more directional in the high frequencies than in the low frequencies. In fact, the antenna radiation patterns depend on the frequency. Naturally, there will be a situation where the vectorial transfer function will depend on the direction aimed at. Another way of addressing the problem consists of saying that a UWB antenna is "small » for the low frequencies and "big" for the high frequencies. The frequency stability of the radiation pattern is therefore a fundamental problem, which means that the shape of the pulse transmitted is unstable from an angular point of view.

One final limitation on the widening of the bandwidth lies in the size of the antenna. That can be understood as follows: the electromagnetic radiation of the antenna can be broken down into a base of spherical modes. When the currents transiting on the antenna are coupled to those modes, there is radiation. For a small antenna, only the modes in the lowest orders are likely to be coupled. The low frequency of an antenna is often inversely proportional to the greatest size of the antenna. Any attempt to extend the bandwidth towards the low frequencies of less than a hundred megahertz or so comes up against large size antennas.

As pulsed operation of antennas is little used, the prior design of an antenna using a digital design tool is essential.

Various characteristics must therefore be observed simultaneously for an aerial to match a UWB application. The parameters enabling the frequency and temporal definition of the antenna are, essentially, its input impedance, its gain, its radiation patterns and the resultant bandwidth.

The power holding of the antenna is linked to its voltage strength. The pulses radiated are very short. The energy absorbed by the antenna is therefore very low. Even in the case of high repetition rates, generally speaking there is no danger of overheating of the antenna. However, the constraints related to the dielectric strength of the radiating element very often means that its geometric dimensions must be modified or dielectric materials added (liquid, gas or solid) to withstand the high voltages applied, ranging from a few dozen kilovolts to several hundred kilovolts as the case may be. Modification of the element must 
not adversely affect its electromagnetic performance. These aspects of voltage strength must therefore be taken into conditions in the design of the antenna.

\section{Valentine antenna: high power design for transient applications}

\subsection{Principle of a travelling wave antenna}

The radiation principle of the Valentine antenna is that of a travelling wave antenna. Instead of standing waves or resonant antennas which exhibit current and voltage standing wave patterns formed by reflections from the open part of their structure, travelling wave antennas are designed to form travelling wave (uniform) patterns in current and voltage by properly terminating the end of the structure so that reflections are minimized if not completely eliminated (Balanis, 2005).

In practice, the Valentine antenna was designed to guide the electrical field from the antenna input to its end. The radiation is built up during the propagation of the transient current on the antenna from the input impedance $(50 \Omega)$ to the plane wave impedance in air $(120 \Pi \Omega)$. Figure 5 illustrates the radiation principle of the Valentine antenna.

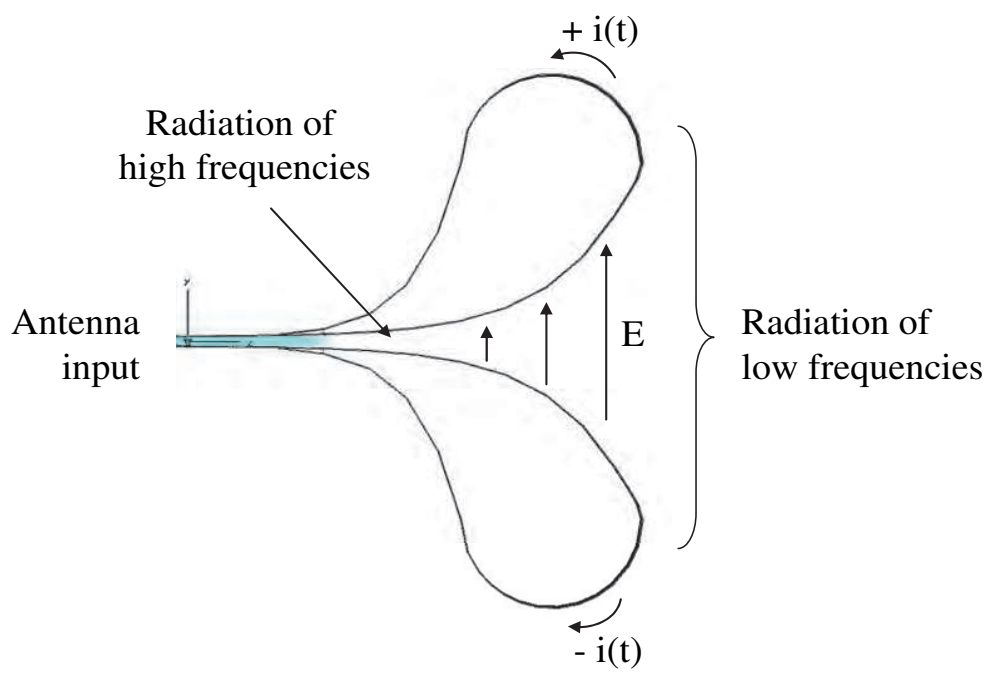

Fig. 5. Radiation principle of the Valentine antenna

This antenna consists of two brass strips curved along a specific profile. The input of the antenna is a symmetrical $50 \Omega$ double strip transmission line. A dielectric part between the two strips ensures a dielectric strength for a short pulse width (in the order of a few nanoseconds). After this line section, the two strips spread symmetrically according to an exponential profile and return back to the input within a circular form. The width of the strips is not constant and increases as the strips move away. The diameter of the rounded part has been increased in order to minimize the current reflections from the end of the antenna and to improve the radiation of low frequencies. This structure is reinforced by a dielectric material which has a dielectric permittivity close to one so as to minimize the perturbations of the high frequency radiation. 


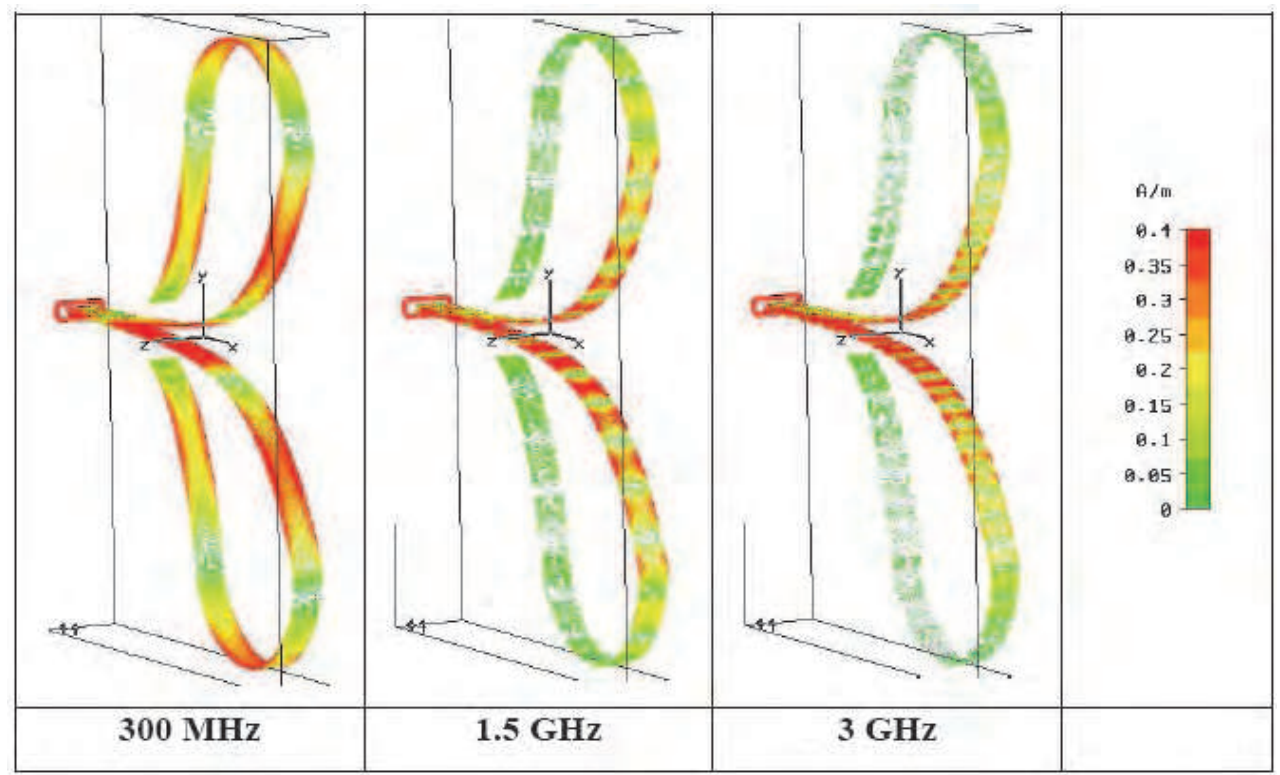

Fig. 6. Surface current distribution on the Valentine antenna

Radiation starts when the pulses reach the zone where the double-strip flares at the beginning of the exponential profile. High frequencies are radiated first and the low frequencies towards the end of the antenna. Part of the low frequencies is not radiated and returns to the generator. Polarization of the radiated electric field is mainly rectilinear and vertical for a vertical position of the antenna (as it can be seen in figure 5).

Figure 6 illustrates the current distribution (which is the origin of the radiation) on the antenna for $300 \mathrm{MHz}, 1.5 \mathrm{GHz}$ and $3 \mathrm{GHz}$. At $300 \mathrm{MHz}$, currents flow over the whole structure. The antenna aperture used to calculate the far-field zone (Fraunhoffer zone) corresponds to its higher dimension, which is $110 \mathrm{~cm}$. At $1.5 \mathrm{GHz}$, currents fade away as they reach the rounded part. The antenna aperture is then equivalent to around $85 \mathrm{~cm}$. At $3 \mathrm{GHz}$, the surface covered by the currents is still reduced. The antenna aperture becomes $63 \mathrm{~cm}$. Consequently, the far-field area depends on the frequency for travelling wave antennas. Here, the far-field zone, from which the wave can be considered as a spherical wave (centered on the antenna phase center), is calculated for the highest frequency and is equal to $9 \mathrm{~m}$.

\subsection{The "Tulipe": impedance and geometrical matching}

The structure of the Valentine requires a $50 \Omega$ double strip feeding section. For the antenna to be associated with the $50 \Omega$ coaxial output of the HPP generator, a "Tulipe" transition has been designed. This transition provides both a geometrical transformation between those two line types and ensures a good impedance matching around the characteristic impedance $(50 \Omega)$. It has the advantage of enabling characterization of the antenna with classic measurement devices, such as a spectrum analyser, which have $50 \Omega$ coaxial test interfaces. 
High voltage considerations must be taken into account for HPP applications. To ensure good dielectric insulation, many materials can be considered such as oil, gas and solid dielectrics. For each material, the dielectric strength of a homogenous gap structure is generally given in dc operation or for a normalized pulse voltage (Malik, 1998). However, these values are not directly available in our application. They are in fact typically used for pulse durations longer than those of interest here (less than 1ns) and for slow rise times. Their extrapolation to faster rise times and shorter pulse widths is not therefore clearly defined. Moreover, these values are often deduced for single-shot operations, whilst the interest here is in repetitive operations (as fast as hundreds of hertz). Finally, these values have been established for homogenous spark gap purposes and not for a large panel of structures which may entail certain field reinforcements. The use of a solid dielectric for the initial experimental tests was excluded because of the difficulty of its maintenance in the event of a failure. Oil is commonly preferred to gas to obtain a high dielectric strength with a relatively simple mechanical implementation.

However, there are many simple calculations to design the transition. To estimate the transition dielectric strength, it is possible, in an initial approach, to use the formula (3) written by Adler (Adler, 1991) for short pulse operation where $t_{63}^{1 / 3}$ is the pulse duration at $63 \%$ of the peak voltage applied to the line:

$$
E_{\max }=\frac{0.48}{t_{63}^{1 / 3} \cdot A^{0.075}}
$$

$E_{\max }$ is the maximum electric field in $\mathrm{MV} / \mathrm{cm}$ and $A$ is the inner conductor area of the coaxial line in $\mathrm{cm}^{2}(A=\pi d / l$, where $d$ is the inner conductor radius and $l$ the transition length. The above rule applies to the case where the inner conductor is positive. For repetitive pulses, Farr (Farr, 1994) recommends the use of the standard formula (1) and that the maximum field $E_{\max }$ be reduced by a factor of four in order to estimate the dielectric strength at a repetition rate close to $1 \mathrm{kHz}$. Moreover, for the transition design, it is essential to take the bandwidth into account. While dielectric strength considerations push the design towards large dimensions, bandwidth considerations push the design towards minimizing the dimensions in order to transit short pulses without damaging the rise time. A trade-off has to be found.

According to Foster (Foster \& Tun, 1995), the length of such a transition must be a one quarter of the lowest frequency wavelength. Farr gives also a simple formula (4) concerning the rise time which can be preserved in such a transition as a function of the numerous transition dimensions:

$$
t_{r}=\frac{\pi^{2}}{2} \frac{\sqrt{\varepsilon_{r}} R^{2}}{l \cdot c}
$$

$\varepsilon_{r}$ is the relative dielectric permittivity of the insulating material, $R$ is the output conductor inner radius of the transition coaxial part, $l$ is the transition length and $c$ is the speed of light. Figure 7 is a $3 \mathrm{D}$ illustration of a longitudinal section of an arbitrary designed Tulipe transition. The design and electromagnetic simulation of the transition and antennas presented in this paper have been performed with the transient solver of Microwave Studio, the 3D electromagnetic software of the CST Company. 


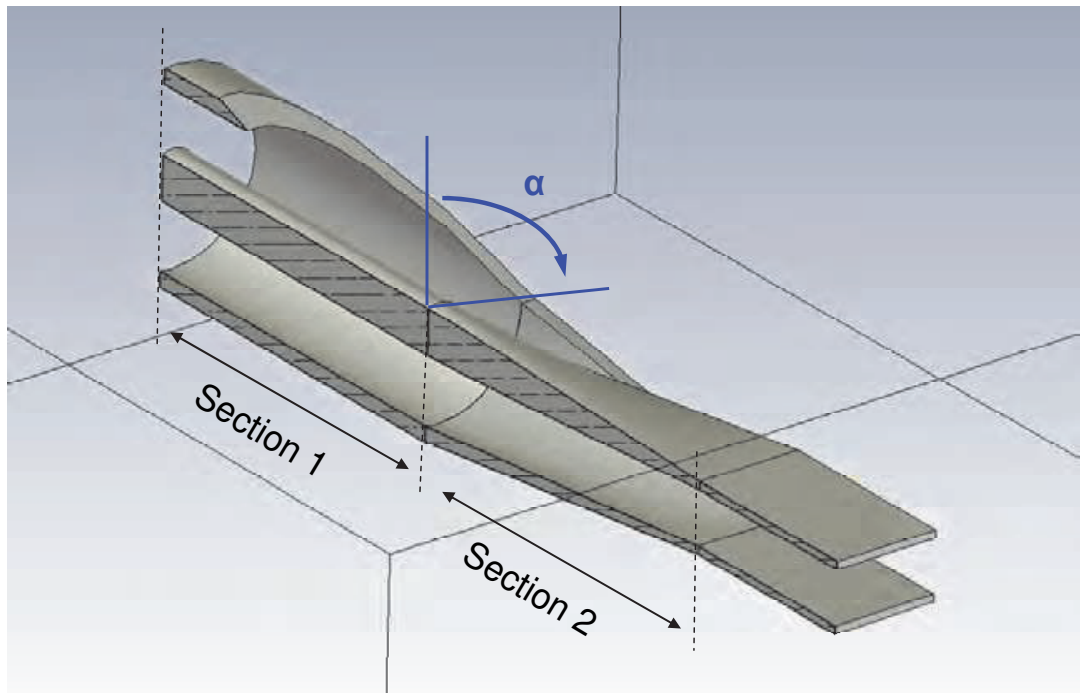

Fig. 7. 3D schematic diagram of the Tulipe transition

The length and radial dimensions of the transition are of great importance to transform a coaxial TEM field into a double-strip TEM field in the frequency spectrum concerned. Figure 8 shows the evolution of the electric field lines in the transition for several cut-away views along the $\mathrm{z}$-axis (a, b, c and d).

In the first section of the transition (see section 1 in figure 7), the outer conductor of the coaxial line is opened up to a semi-angle $\alpha=90^{\circ}$ and the inner conductor diameter remain unchanged. The characteristic impedance in this section 1 increases as the semi-angle a increases. In the second section (see section 2 on figure 7), the outer conductor changes into a rectangular shape which will become the lower conductor of the double-strip line. The inner conductor of the coaxial line becomes, by a series of elliptical profiles, the upper conductor of the double-strip line.

Electric and magnetic lines remain in a TEM mode. Figure 8 shows the electric field lines arrangement for different abscissa along the transition. This analysis shows that some poor electric field reinforcements could appear in the transition. These reinforcements could cause dielectric breakdown in the case of high voltage applications.

The impedance along the Tulipe is evaluated by the mean of TDR (Time Domain Reflectometry) analysis. In order to keep it constant, dielectric materials with the same dielectric permittivity in the upstream coaxial line, the Tulipe and the downstream doublestrip line must be used as soon as possible.

\subsection{Design for an ultra compact high power broadband source \\ 2.3.1 The deployed Valentine antenna}

The project required the development of a new UWB antenna which is small with respect to the overall dimensions of the system and able to radiate with high gain, high voltage transient monopolar and bipolar pulses at high repetition rates. Dimensioning of this antenna was performed with the help of CISTEME and the XLIM laboratory (Limoges University, France). 

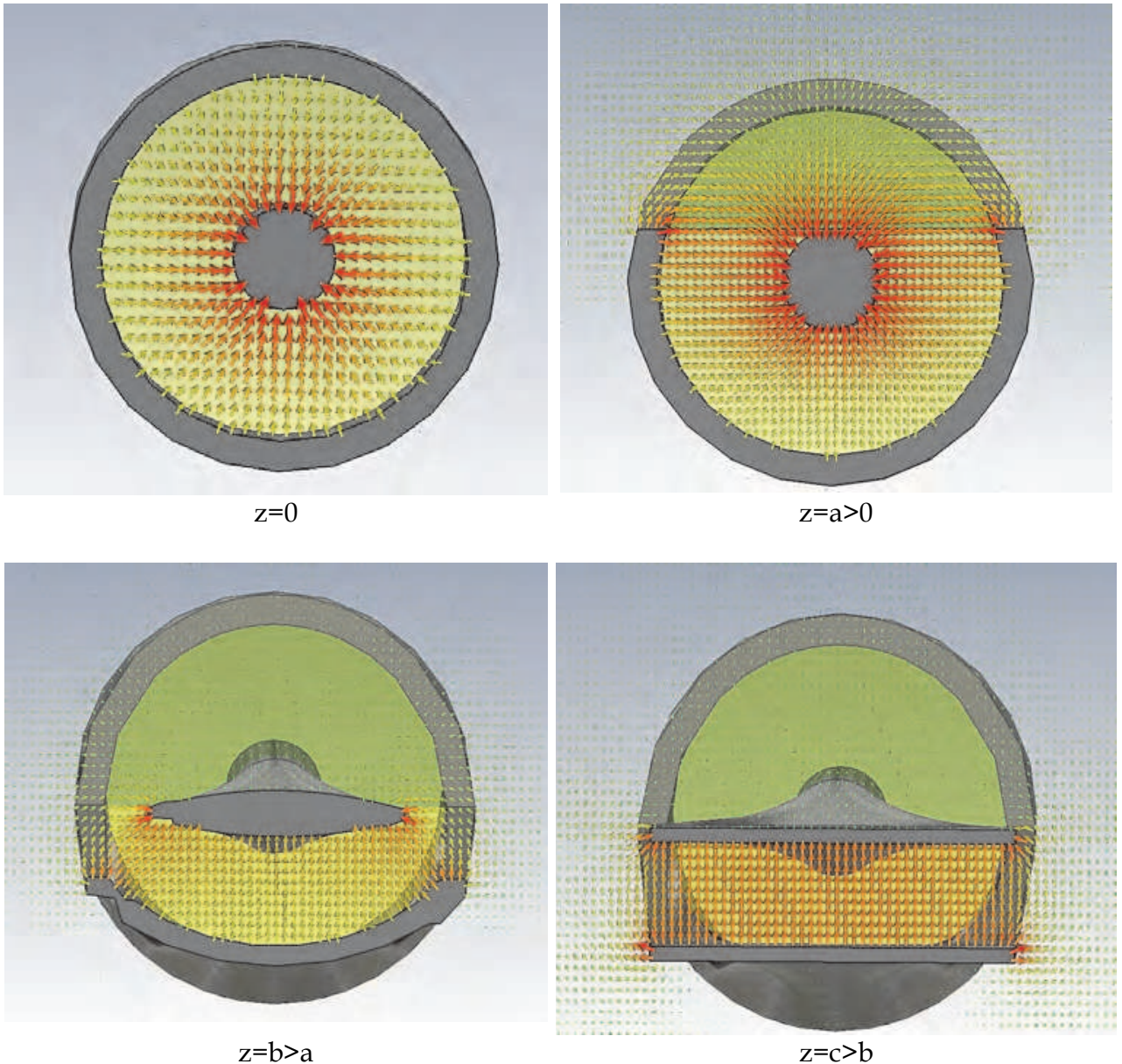

Fig. 8. TEM field evolution in the Tulipe transition

Inspiration for the design presented here came from the existing Valentine antenna. The basic principle to reach a high degree of compactness is to deploy the antenna when it is used and fold it away when the system is off. For reasons of confidentiality, the overall dimensions cannot be given in this paper.

Just as the Valentine presented in section 2.1, the deployed Valentine antenna consists of a coaxial-to-double strip transition and two metal strips curved along a specific profile separated by an insulating plate. The input transition transforms the $50 \Omega$ coaxial geometry of the generator output into a $50 \Omega$ stripline geometry. The two strips of the line then flare symmetrically according to an exponential profile and return back to the ground linearly. The strip widths are not constant and increase as the strips move away. The transition is filled with oil $\left(\varepsilon_{\mathrm{r}}=2.3\right)$ to ensure good dielectric strength. The space in the stripline is filled with an insulating plate which has the same dielectric permittivity. A 3D schematic diagram of the antenna is presented in figure 9. 


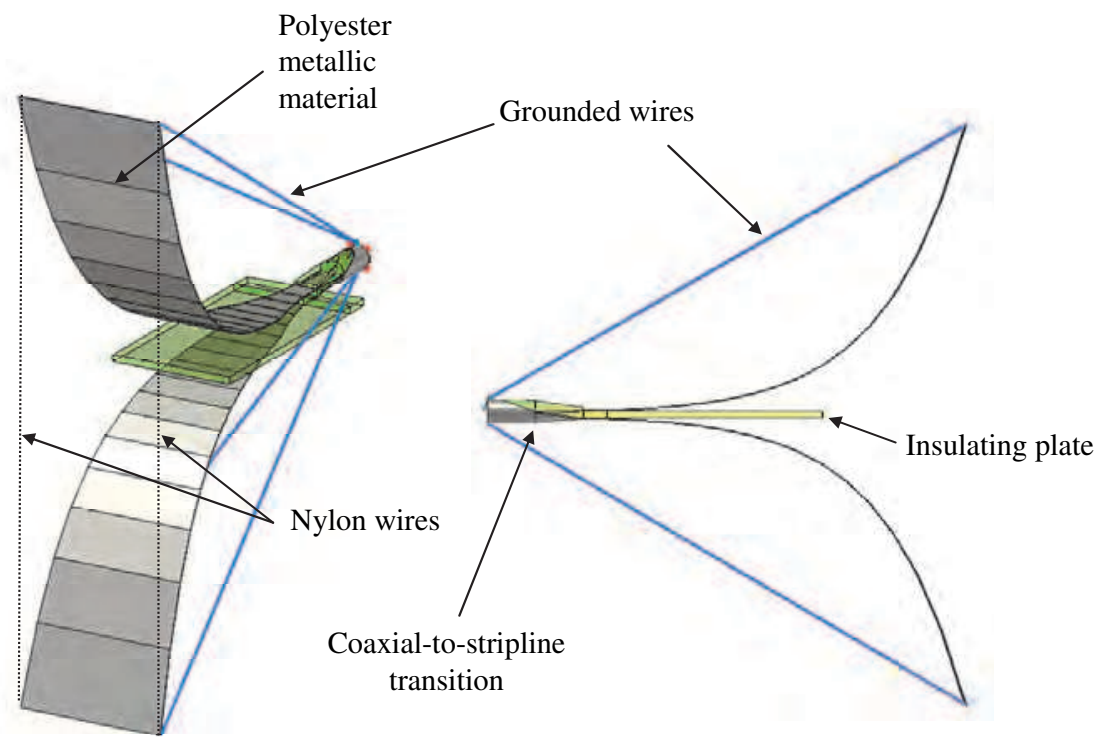

Fig. 9. Deployed Valentine antenna

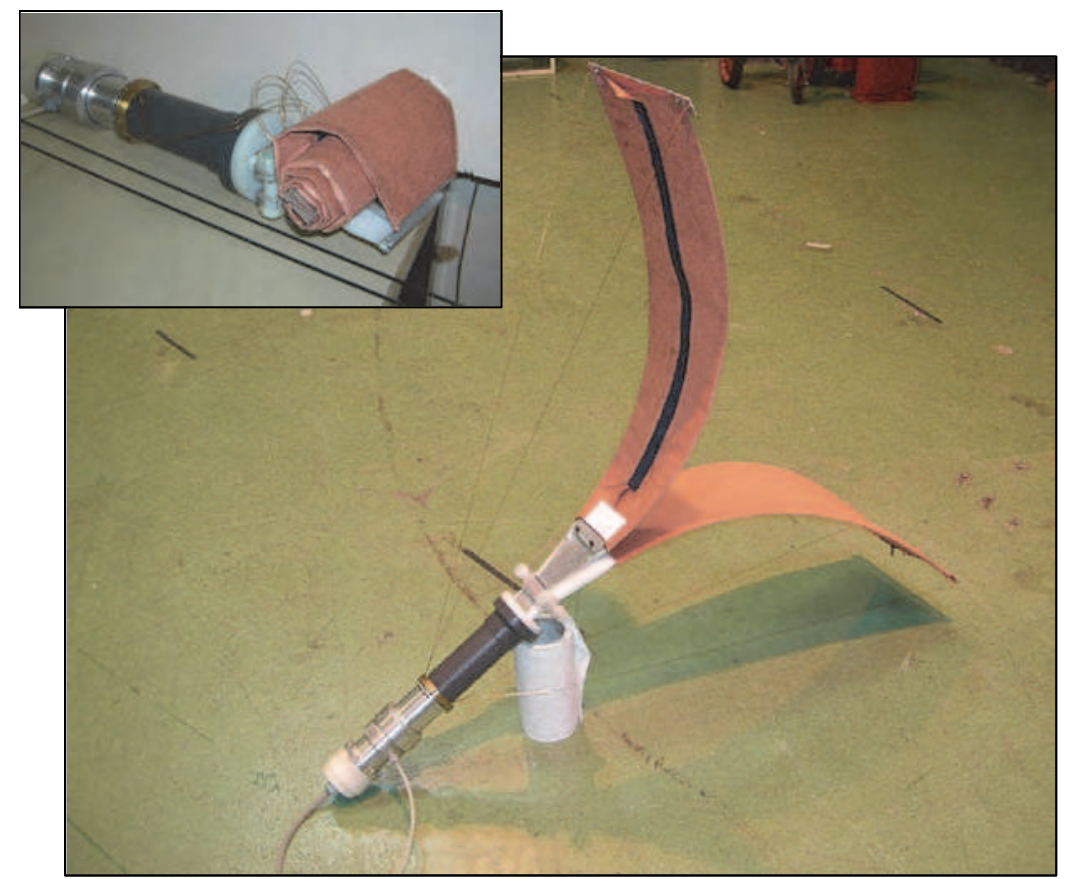

Fig. 10. Photographs of the deployed Valentine antenna 
Figure 10 shows photographs of the deployed Valentine antenna (connected to a section of an HPP generator). The Tulipe transition is inserted into a cylindrical PVC tight container. A polyester metal coated material was chosen to make the two strips. The specific profile of a strip is maintained by stretching a set of two carbon shafts with two nylon wires and two copper grounded wires. These two copper wires, directly linked to the ground, avoid the electric charge of the antenna for repetitive tests and improve roughly the electromagnetic performance (especially the radiation patterns for lower frequencies). They highly contribute to the mechanical support of the antenna when it is deployed.

The two strips are fastened to the transition by means of a mechanical clamp to ensure an excellent surface continuity between the "solid" part of the strips and the "supple" part.

Assembly and disassembly can be performed in three minutes using the zip mounted on each strip.

By mean of a TDR study, the shapes of the transition and its dielectric material have been improved. The impedance variation is small over $50 \Omega$. Its value varies between $42.5 \Omega$ and $58 \Omega$.

The calculated impedance along the Tulipe transition is shown in figure 11.

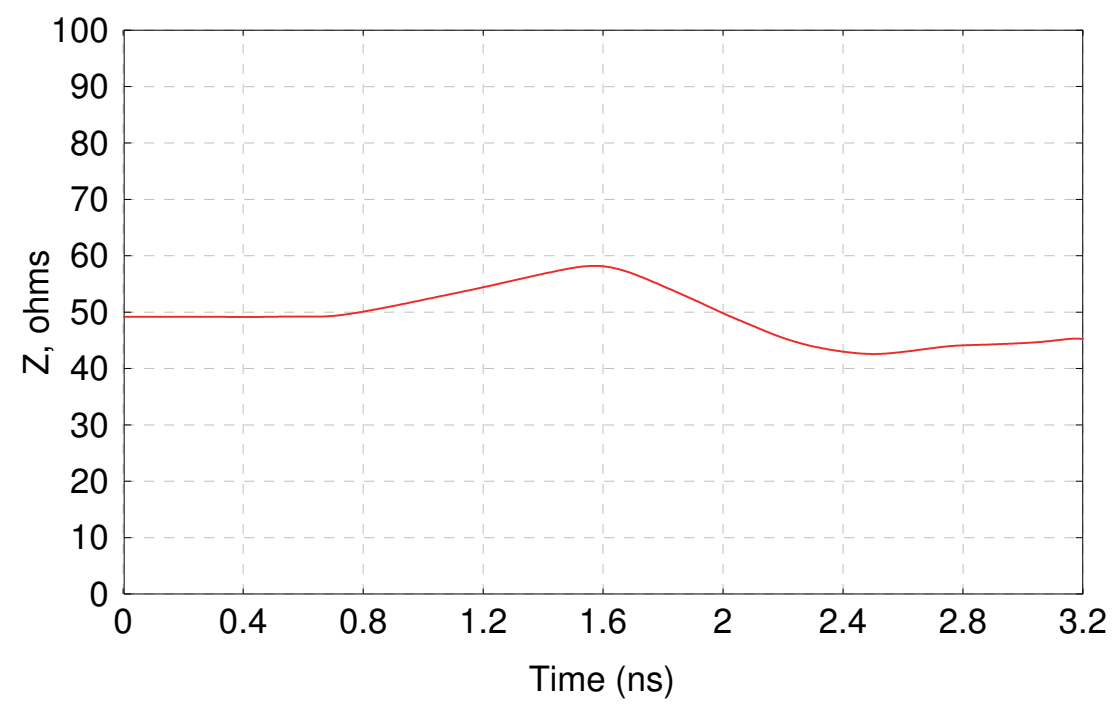

Fig. 11. Impedance variation along the Tulipe transition

\subsubsection{Electromagnetic characteristics}

The radiation principle of this antenna is that of the classic Valentine antenna. The electromagnetic energy is guided in a Transverse Electro-Magnetic mode from the coaxial input to the stripline section before being radiated. Radiation starts when the pulse reaches the zone where the two sides of the stripline flare and continues during the propagation of the transient currents along the surface of these two strips. The high frequency part of the spectrum is radiated first and the low frequency part more at the end of the antenna. The fact that the two strips are shortened is a compromise between the size, the ease of assembly and the electromagnetic performance of the antenna. 


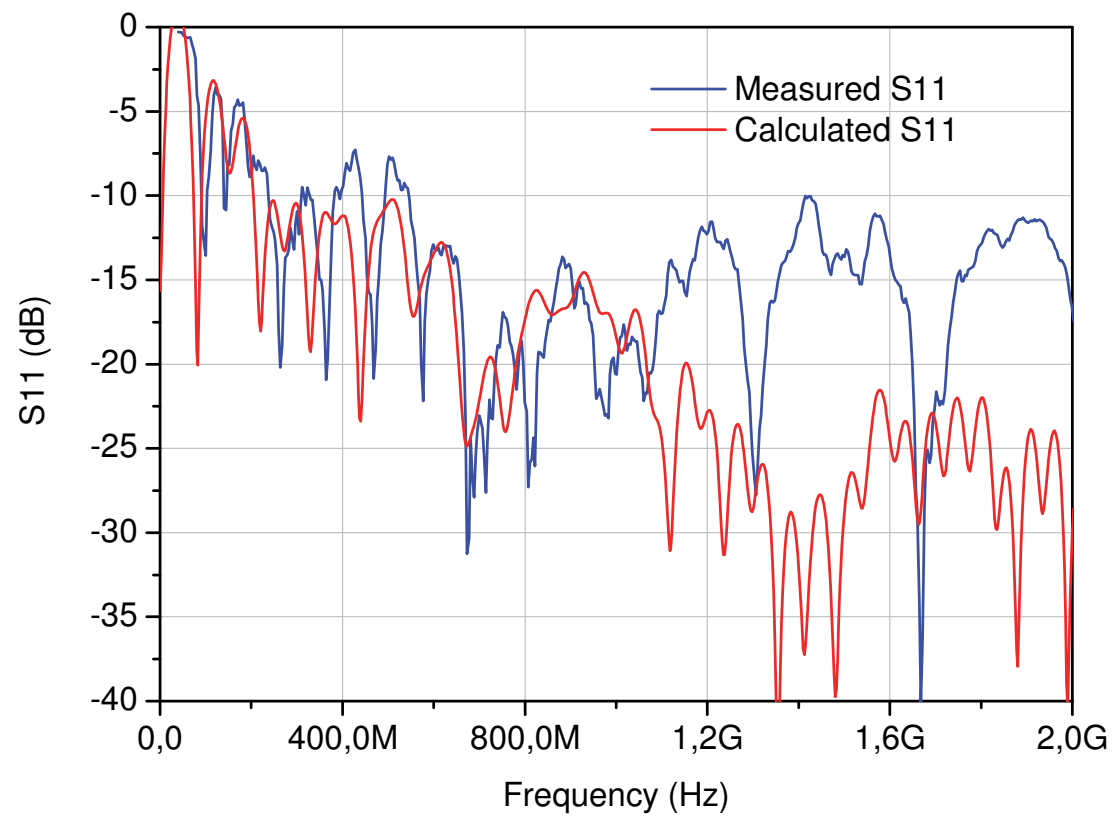

Fig. 12. $S_{11}$ parameter

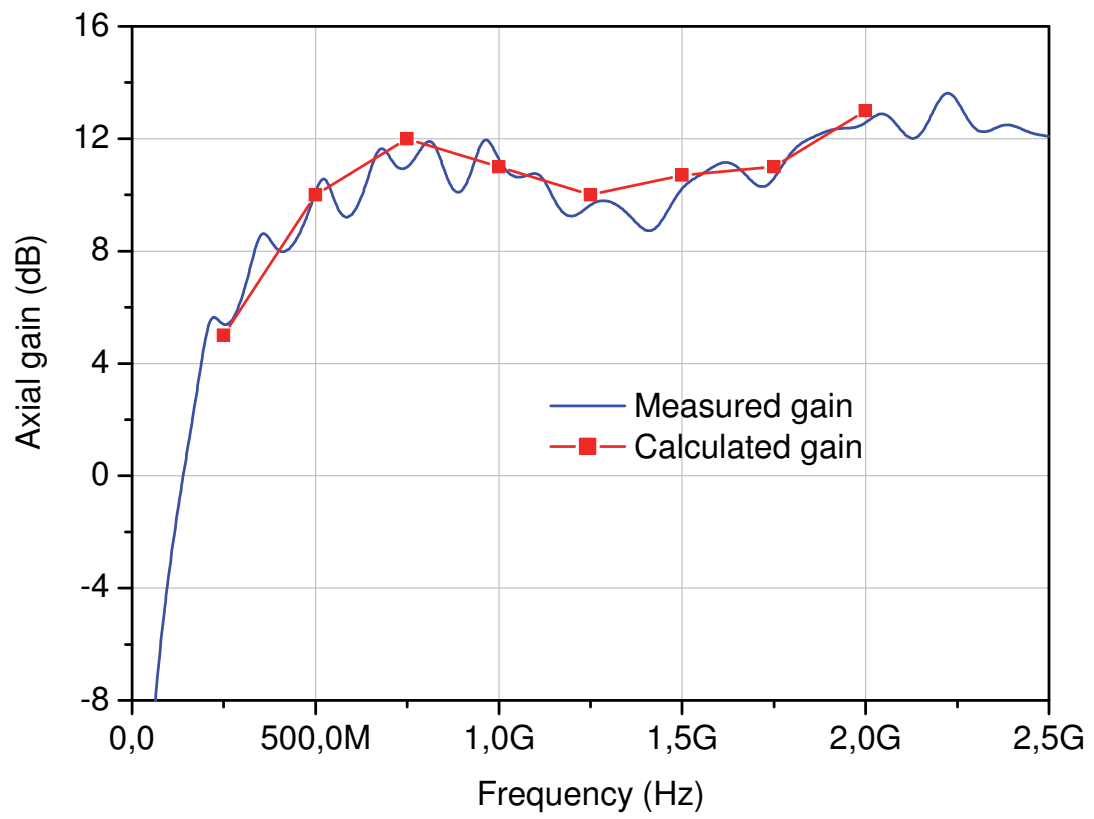

Fig. 13. Axial gain obtained 
Polarization of the radiated electric field is mainly rectilinear and vertical for a vertical position of the antenna (see the position in figure 9).

Figure 12 shows the measured and calculated $S_{11}$ reflection parameter of the antenna in the frequency range of $300 \mathrm{kHz}-2 \mathrm{GHz}$. Calculations for the design of this antenna were made using the transient solver of the CST Microwave Studio time-domain electromagnetic software.

The results are relatively similar from the low frequencies up to $1 \mathrm{GHz}$. A $S_{11}$ maximum level of $-10 \mathrm{~dB}$ is obtained in the frequency band of $250 \mathrm{MHz}-2 \mathrm{GHz}$ except at frequencies between $400 \mathrm{MHz}$ and $550 \mathrm{MHz}$ where the measured $S_{11}$ oscillates with a maximum of $-7.5 \mathrm{~dB}$.

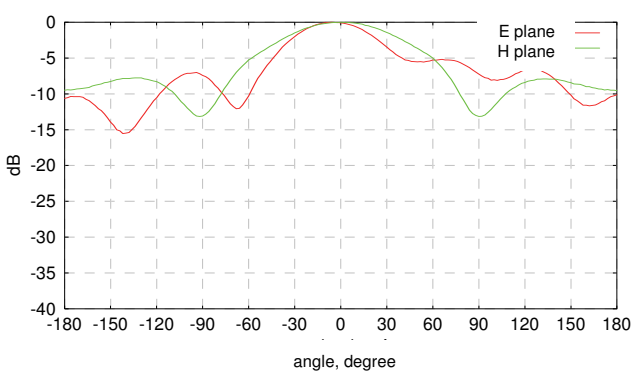

(a) $\mathrm{f}=250 \mathrm{MHz}$

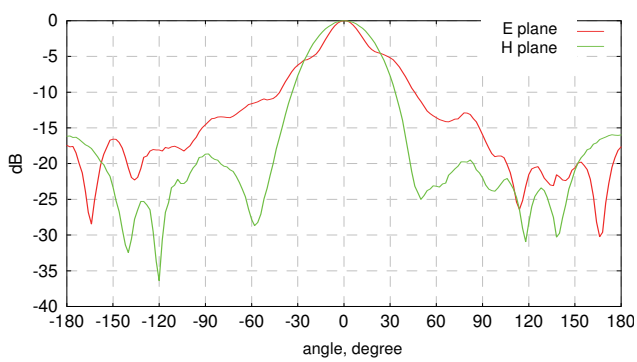

(c) $\mathrm{f}=750 \mathrm{MHz}$

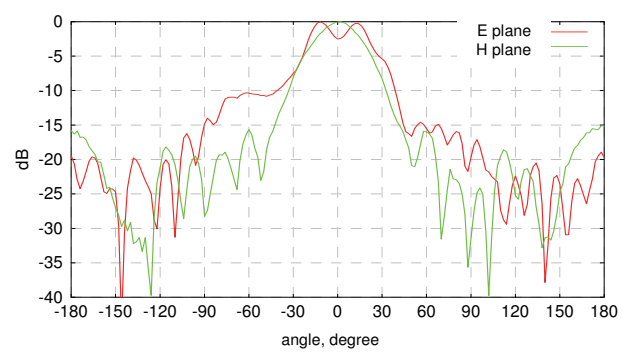

(e) $\mathrm{f}=1.25 \mathrm{GHz}$

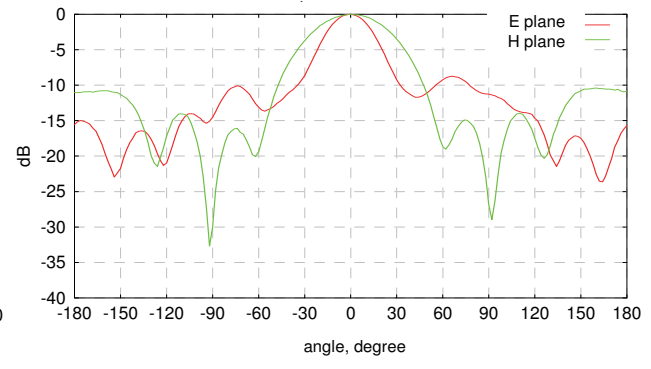

(b) $\mathrm{f}=500 \mathrm{MHz}$

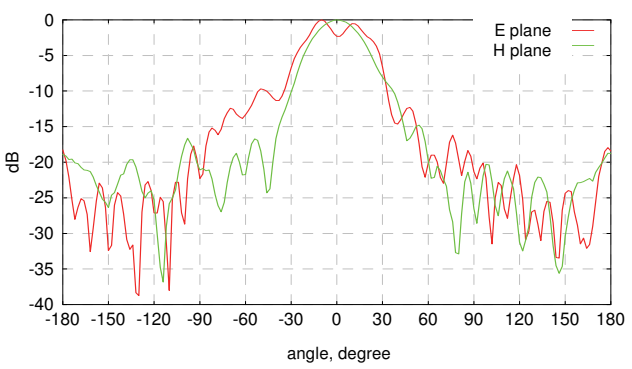

(d) $\mathrm{f}=1 \mathrm{GHz}$

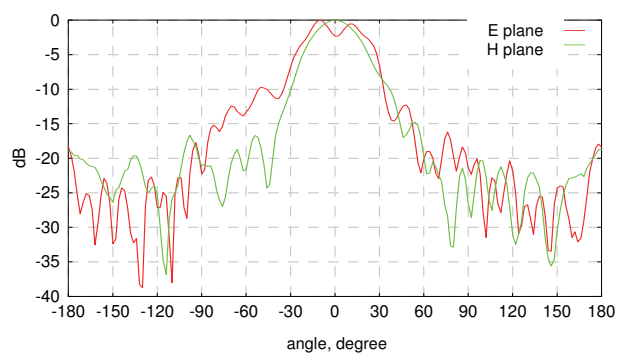

(f) $\mathrm{f}=1.5 \mathrm{GHz}$

Fig. 14. Radiation patterns in $\mathrm{E}$ and $\mathrm{H}$ planes between $250 \mathrm{MHz}$ and $1.5 \mathrm{GHz}$ 
To analyze its transient performance levels, the antenna was used as a transmitting antenna and powered by a pulse generator (Kentech APG1). The characteristics of the pulse with a $50 \Omega$ load are: an output voltage of $220 \mathrm{~V}$, a rise time of $116 \mathrm{ps}$ and a FWHM of $147 \mathrm{ps}$. A wellknown UWB receiving antenna is placed in front of the deployed Valentine antenna and connected to a $8 \mathrm{GHz}$ real time oscilloscope (Tecktronix TDS 6804 B). Antennas are positioned facing each other at a distance of $7.85 \mathrm{~m}$ at a height of $2.75 \mathrm{~m}$.

The axial gain, shown in figure 13, is deduced from these transient measurements for a frequency range of $300 \mathrm{kHz}-2.5 \mathrm{GHz}$. It is compared to the calculated gain of a classic Valentine antenna with the same $\mathrm{a}, \mathrm{b}$ and $\mathrm{c}$ dimensions.

Good agreement can be seen between these results showing that the new deployed structure of this new Valentine antenna does not degrade the electromagnetic spectrum of the source. The gain is more than $8 \mathrm{~dB}$ in the frequency range of $330 \mathrm{MHz}-2.5 \mathrm{GHz}$.

Radiation patterns were also determined using transient measurements for each direction $\left(10^{\circ}\right.$ steps from $0^{\circ}$ to $\left.360^{\circ}\right)$. The radiation patterns measured in the E-plane and the H-plane at $250 \mathrm{MHz}, 500 \mathrm{MHz}, 750 \mathrm{MHz}, 1 \mathrm{GHz}, 1.25 \mathrm{GHz}$ and $1.5 \mathrm{GHz}$ are shown in Figure 14 (a)-(f). The main lobe is narrower in the $\mathrm{H}$ plane than in the $\mathrm{E}$ plane and in the H-plane becomes narrower with the increase in frequency. The shape of the radiation pattern in the E-plane depends on the profile followed by the metallic strips. It can prove the dissymmetrical form of the pattern in this plane, perhaps due to an incorrect shape of the antenna during the test. Back radiation is close to $-20 \mathrm{~dB}$ for the higher frequencies.

\section{Optimized ultra-wideband array design}

\subsection{Introduction}

Usually, the radiation pattern of a single antenna is relatively wide (especially for broadband antennas) and each element provides low values of directivity. Enlarging the dimensions of the antenna often leads to more directive characteristics. Another way to enlarge the dimensions of the antenna, without necessarily increasing the size of the individual element, is to form an assembly of radiating elements in an electrical and geometrical configuration.

The total field of the array is determined by the vector addition of the fields radiated by the individual elements. The theoretical array gain then depends directly on the number of antennas as in the expression 5 .

$$
G_{R}=G_{A}+10 \cdot \log (N)
$$

$G_{R}$ and $G_{A}$ are respectively the gain of the full array and the gain of a unit antenna (in $\mathrm{dB}$ ). In this way, when the number of antennas is doubled, the gain increases by $3 \mathrm{~dB}$. That assumes that the current in each element is the same as that of the isolated element (neglecting coupling). This is usually not the case and depends on the separation between the elements. To provide very directional patterns, the fields from the elements of the array must interfere constructively in the desired directions and interfere destructively in the remaining space. Ideally, this can be accomplished, but in practice it is still being examined. In an array of identical elements, many parameters can be used to shape the overall pattern of the antenna. Among them, the most important are:

- the geometric configuration of the overall array

- $\quad$ the relative distance between individual elements

- $\quad$ the excitation amplitude and phase of the individual elements 
- the relative pattern of the individual elements.

The influence that each of the above has on the overall radiation characteristics may be significant to the extent that the design of such an array is always a compromise between each one of them.

It must also be stressed that for high power applications, a unique antenna system needs a means to reduce high dielectric strength constraints. On the other hand, the use of an N antennas array makes it possible to divide the power into the $\mathrm{N}$ antennas.

\subsection{Size optimization of the single element: the $\mathrm{K}$ antenna}

The antenna array presented in this third part consists of $K$ type antennas, the concept of which was defined by the HCEI team in Tomsk (Koshelev et al., 2001) already presented in section 1.2.4.2 of this paper. This antenna was designed to be integrated into a high power electromagnetic wave radiating system.

The antenna was purchased and optimization work performed in particular to reduce its dimensions and to centre its operational band on the required frequency band. The optimization work was performed in simulation using CST Microwave Studio software following a preliminary characterization study of the original antenna carried out by the XLIM laboratory of Limoges University. Figure 15 shows a 3D view of the CST optimized antenna and a photograph of the antenna actually made.
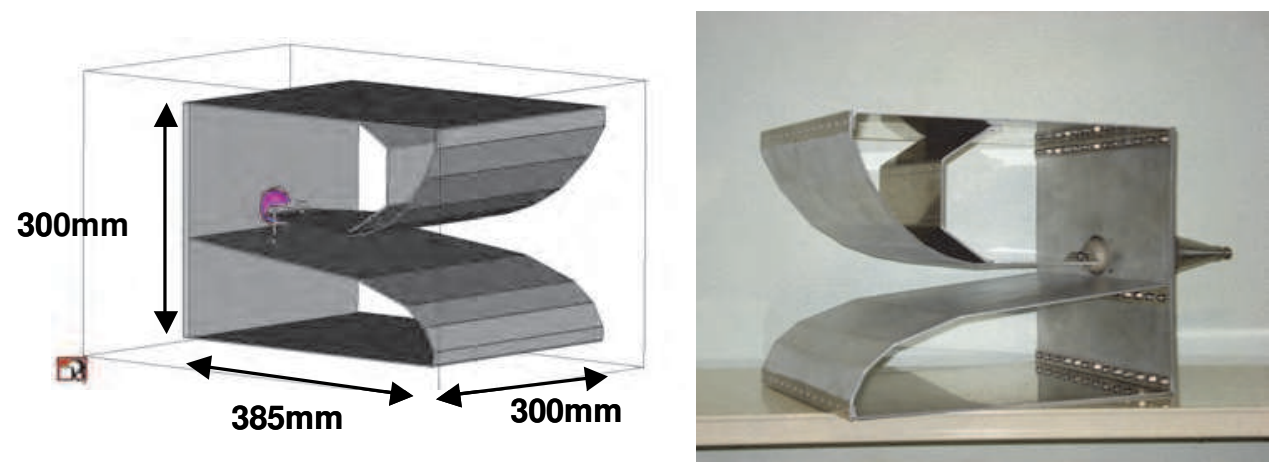

Fig. 15. Optimized K antenna

Optimization of the basic antenna made it possible to widen its frequency band and thereby to make it more compact. The reflection coefficient is shown in Figure 16. A measurement is compared to the network analyzer and the simulation. The frequency band for which a good adaptation of the antenna was obtained $\left(S_{11} \leq-10 \mathrm{~dB}\right)$ is between $320 \mathrm{MHz}$ and $1,16 \mathrm{GHz}$. The adaptation is not as good as in theory: $320 \mathrm{MHz}-1,75 \mathrm{GHz}$. The difference is due to the modeling which fails to take account of the conical part ensuring the coaxial transition $\mathrm{N}$. Moreover, the characteristics of the coaxial connections are different in simulation. The low frequency of the antenna was therefore reduced from $450 \mathrm{MHz}$ (original antenna) to 320 $\mathrm{MHz}$, and the high frequency was boosted beyond $1 \mathrm{GHz}$.

To analyse its transient performance levels, the antenna is used as a transmitting antenna and powered by a pulse generator (Kentech APG1). The characteristics of the pulse at a $50 \Omega$ load are: an output voltage of $220 \mathrm{~V}$, a rise-time of $116 \mathrm{ps}$ and a FWHM of 147ps. Measurement of the E field along the main axis is compared in figure 17 to a simulation 
where the antenna is fed with the same voltage signal. The antenna factor $A F$ (corresponding to the ratio of the electric field peak magnitude $E$ at the distance $r$ by the input voltage peak magnitude $V: A F=\frac{1}{r} \frac{E}{V}$ ) obtained in this case is 1.2.

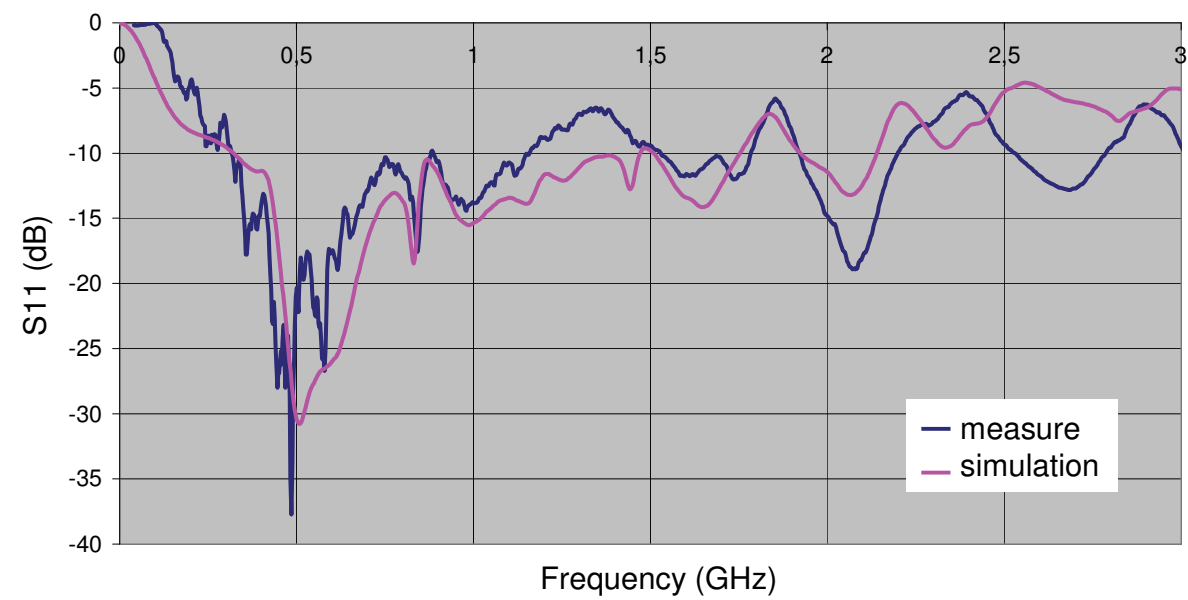

Fig. 16. $S_{11}$ parameter of the optimized $K$ antenna

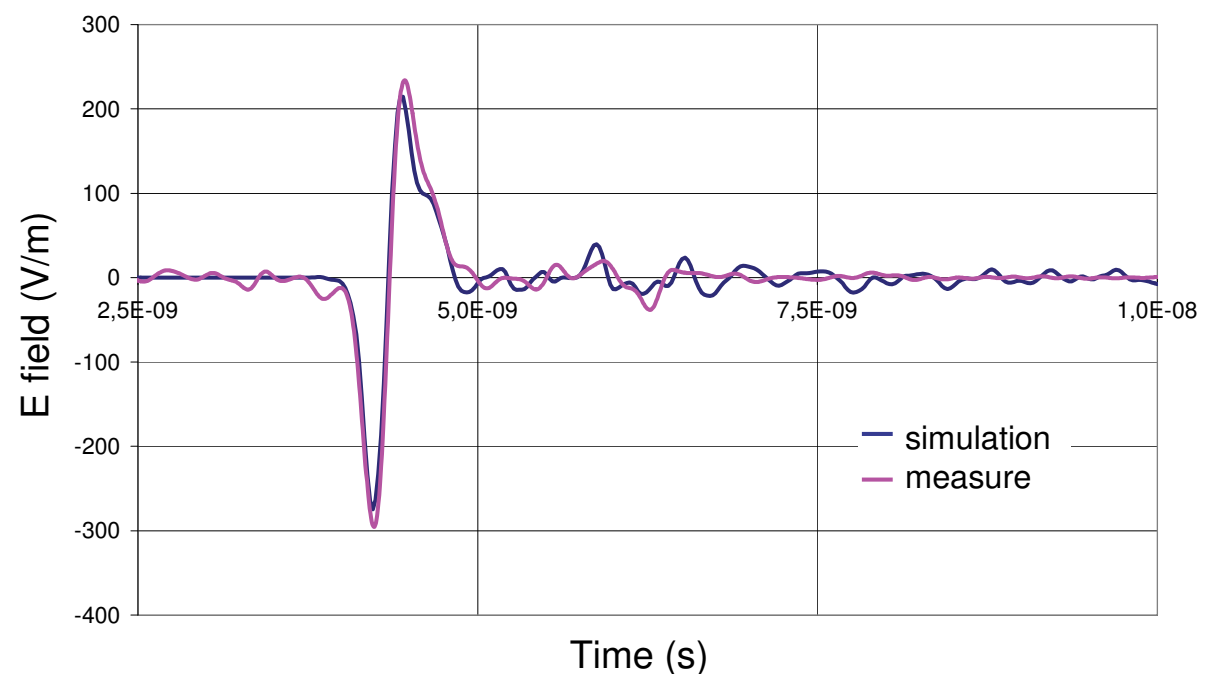

Fig. 17. E-field along the main axis at $1 \mathrm{~m}$

The axial gain is deduced from these transient measurements for a frequency range of $300 \mathrm{kHz}-3 \mathrm{GHz}$. It is compared, in figure 18, to the calculated range.

Radiation patterns were also determined using transient measurements for each direction $\left(10^{\circ}\right.$ steps from $0^{\circ}$ to $\left.360^{\circ}\right)$. The radiation patterns measured in the E-plane and the H-plane are shown in figure 19 as intensity graphs. 


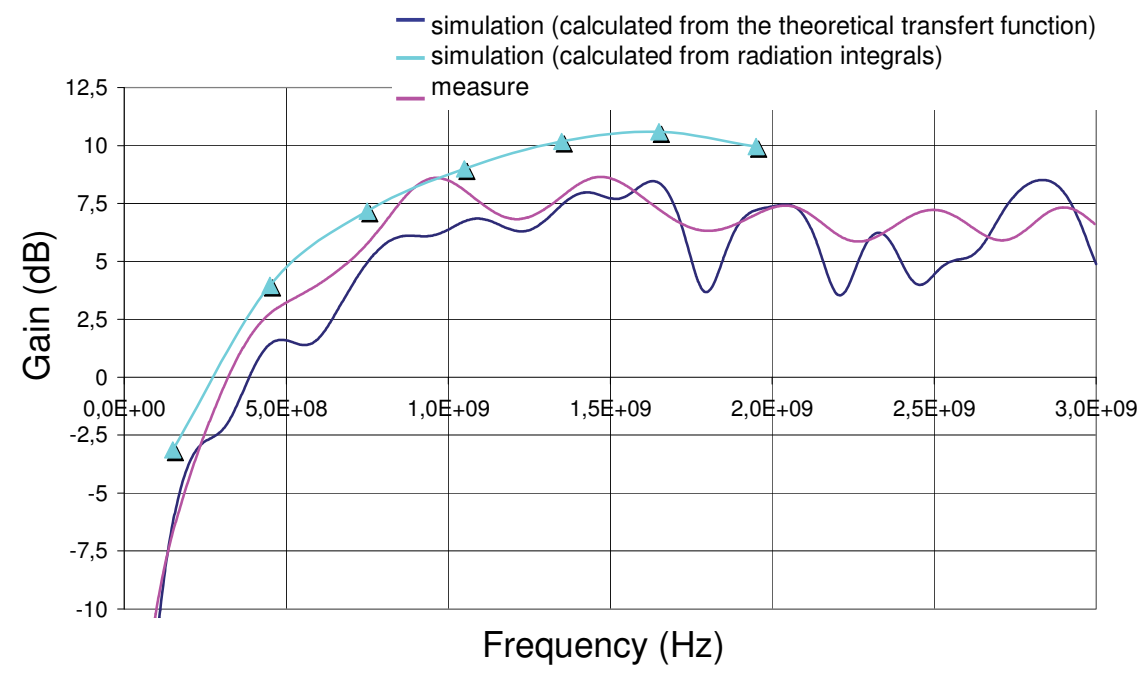

Fig. 18. Gain of the optimized K antenna obtained

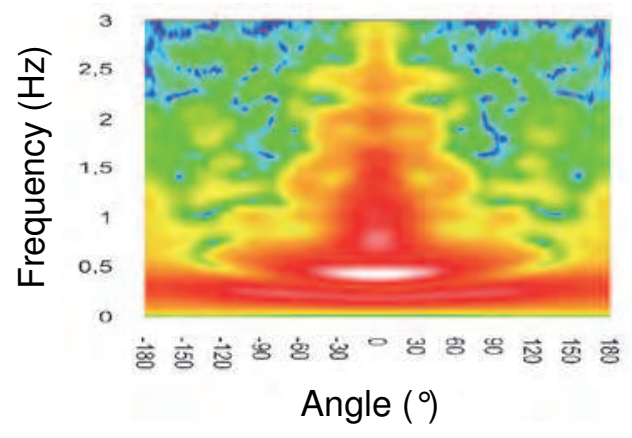

H plane

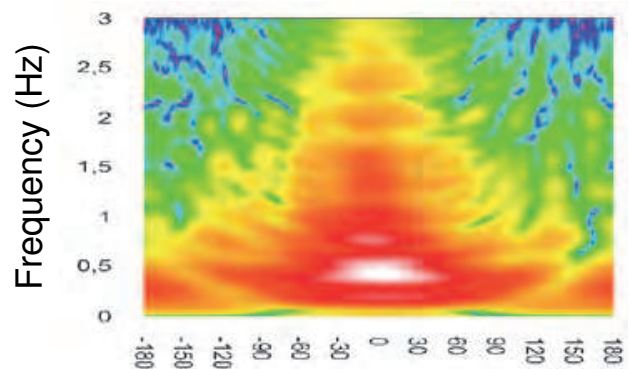

Angle $\left({ }^{\circ}\right)$

E plane

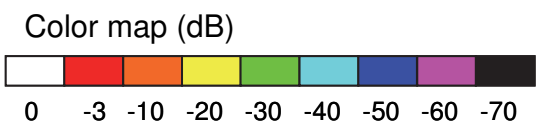

Fig. 19. Radiation patterns in the $\mathrm{E}$ and $\mathrm{H}$ planes

As for the most part of travelling wave antenna, the main lobe of the pattern is narrower in the $\mathrm{H}$ plane than in the $\mathrm{E}$ plane. In each plane, this lobe becomes narrower with the increase in frequency. Back radiation level is less than $-10 \mathrm{~dB}$ from $320 \mathrm{MHz}$ to $750 \mathrm{MHz}$ and less than $15 \mathrm{~dB}$ from $750 \mathrm{MHz}$ to upper frequencies.

\subsection{Electromagnetic characteristics of the optimized UWB array.}

Figure 20 is a photograph of the $\mathrm{K}$ antennas array. It consists of 16 optimized $\mathrm{K}$ antennas in contact. 


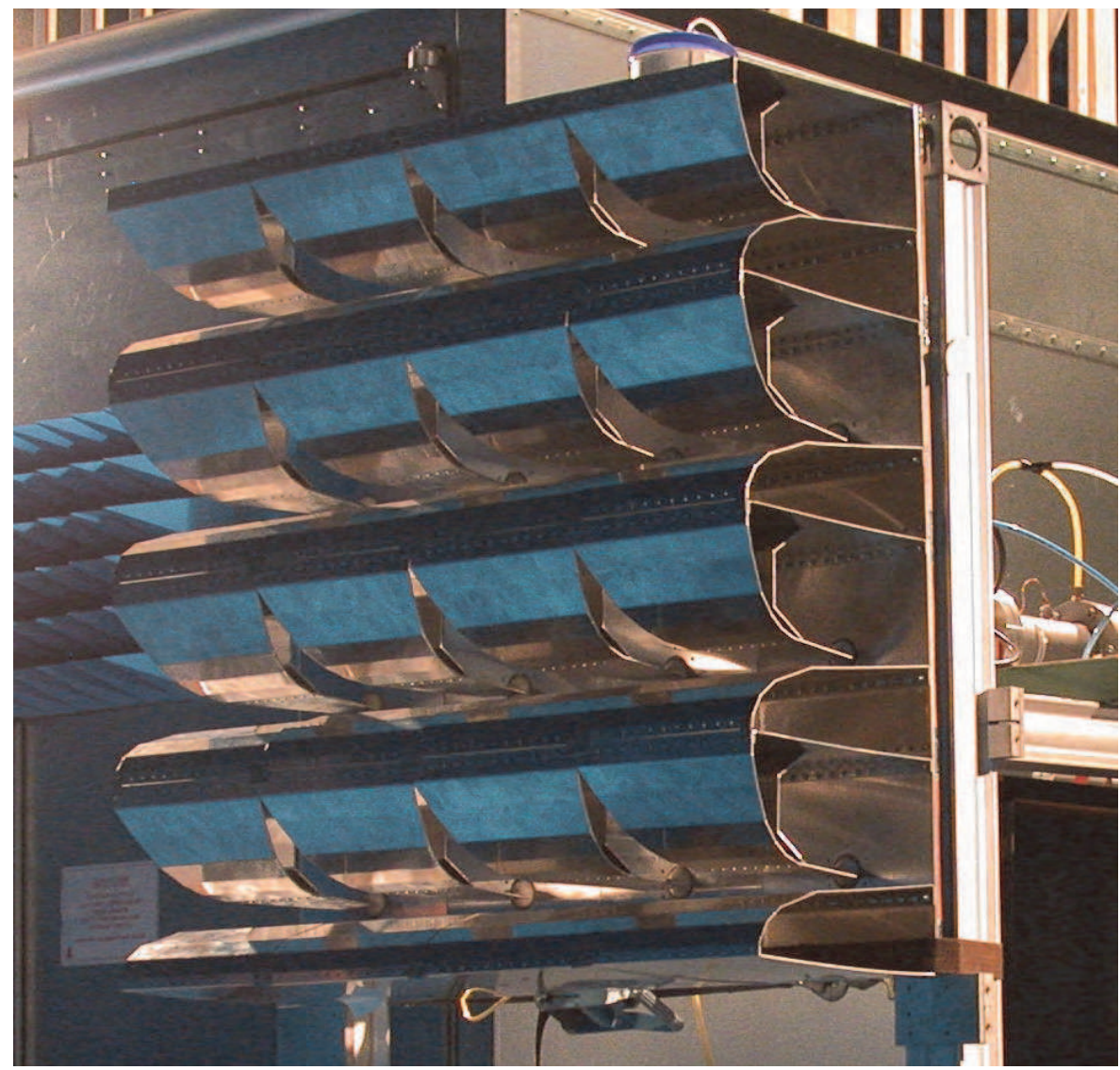

Fig. 20. 16 optimized K antennas array

\subsubsection{Numerical justification of the array arrangement}

Not all the results which contributed to the sizing of the array will be detailed here but only the most representative, in particular those concerning the choice of the vertical spacing $\left(\mathrm{d}_{\mathrm{v}}\right)$ and horizontal spacing $\left(\mathrm{d}_{\mathrm{h}}\right)$ between the antennas.

The study was performed on two vertical and horizontal single dimensional arrays with three and four antennas respectively so as to decouple the induced effects. The study was performed vertically on three distances, of $0,25 \mathrm{~mm}$ and $50 \mathrm{~mm}$.

Figure 21 presents the figure-of-merit (the maximum value of the far-field peak electric field multiplied by the distance) in the axis of the $\mathrm{E}$ plane for the different vertical differences between the antennas when they are powered simultaneously by a 200ps rise time, $1 \mathrm{~V}$ peak, bi-exponential pulse. The figure-of-merit (FOM) in the main axis is identical for the three array configurations. On the other hand, this representation shows the increase in the back radiation with the increase of the distance between the antennas. The variation in the peak level of the field appears as from $\pm 135^{\circ}$. For that reason, it was decided to perform a maximum reduction of the distance $\mathrm{d}_{\mathrm{v}}$ down to the vertical contact between antennas. 

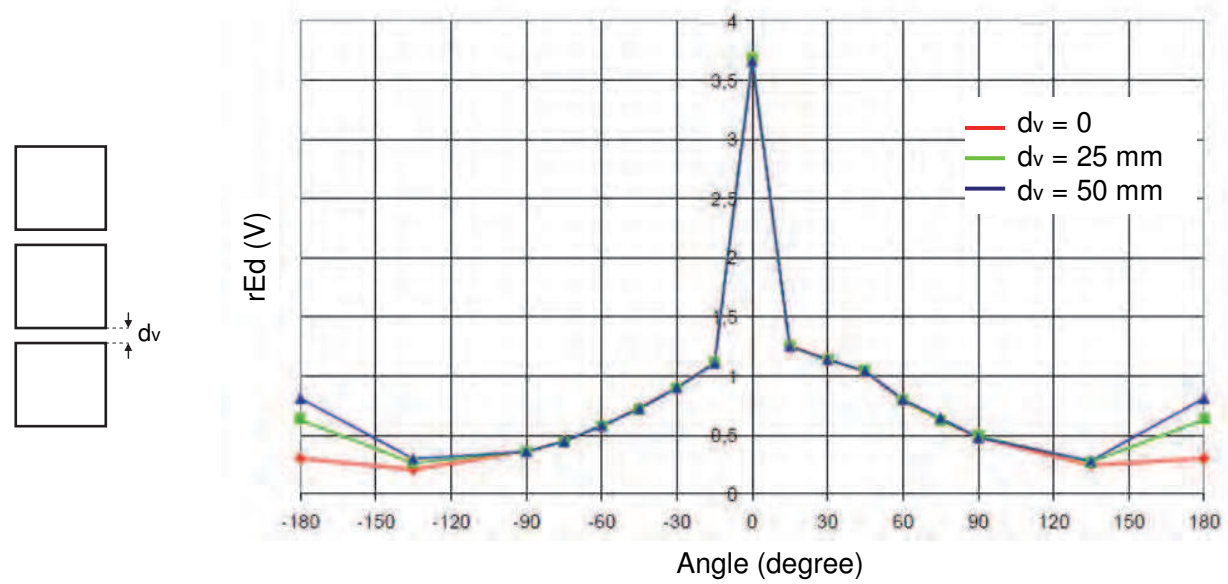

Fig. 21. FOM as a function of the incident angle (for $1 \mathrm{~V}$ antenna feed voltage) - E-plane

The same simple study was performed with a horizontal array of four optimized K antennas. The distance adopts successively the three values of $20 \mathrm{~mm}, 80 \mathrm{~mm}$ and $160 \mathrm{~mm}$.
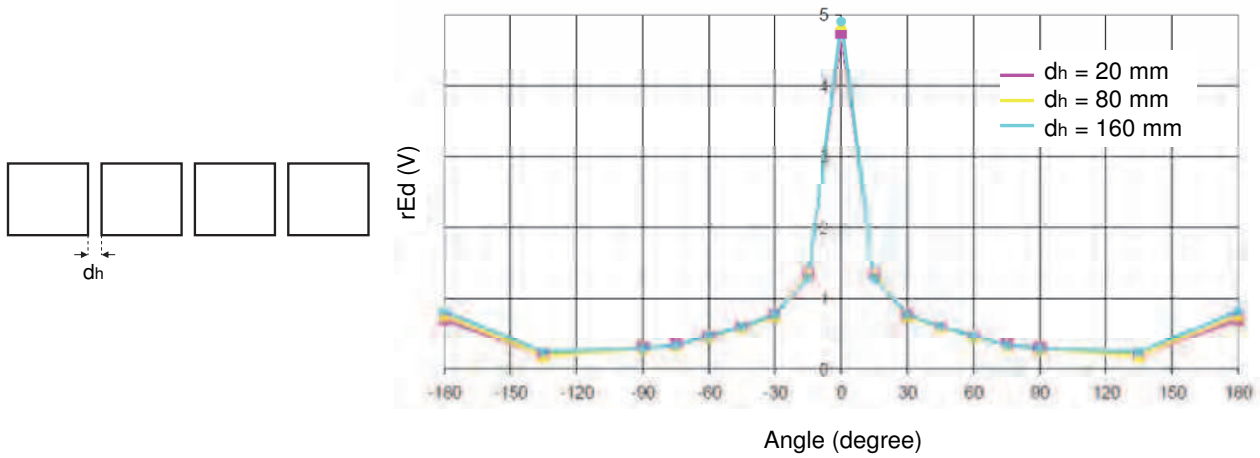

Fig. 22. FOM as a function of the incident angle (for $1 \mathrm{~V}$ antenna feed voltage) - H-plane

The variation in the peak amplitude of the field, according to the angle of observation (shown in Figure 22), evidences that the array makes it possible to focus the radiation. The front/back radiation ratio remains constant irrespective of the spacing between the antennas. The transient radiation does not appear to be degraded although the coupling between the antennas increases with the reduction in the space between the antennas.

Moreover, at the frequencies considered, the spacing of the antennas tends to increase the lobes of the arrays. From the radiation viewpoint, the antennas can therefore be positioned very close to each other.

Given the previous results and then following a modeling study of the various array solutions, the choice was made, in order to observe a certain trade-off between the size and the radiated field level, to reduce the distance between the antennas to the extent that they were in contact with each other. 
To study the influence of the antennas being placed in contact on their adaptation, power was supplied to the port $N^{\circ} 6$ (Figure 23). Given the symmetry used to reduce the necessary computer resources, the symmetrical port was also powered. Consequently, the coefficients calculated are not "true » reflection and coupling parameters. That nonetheless makes it possible to have a general idea of the coupling between the antennas.

The « reflection » coefficient $\mathrm{S}_{66}$ is greater than $-10 \mathrm{~dB}$ over practically the entire frequency band (Figure 23). When the antennas are in contact, the reflections at the low frequencies $(<500 \mathrm{MHz})$ increase. As far as the port $\mathrm{n}^{\circ} 2$ situated next to the port $\mathrm{n}^{\circ} 6$ is concerned, the coupling on this port is high and increases all the more when the antennas are in contact. The ports 1, 3 and 5 are better insulated in the event of the antennas touching.
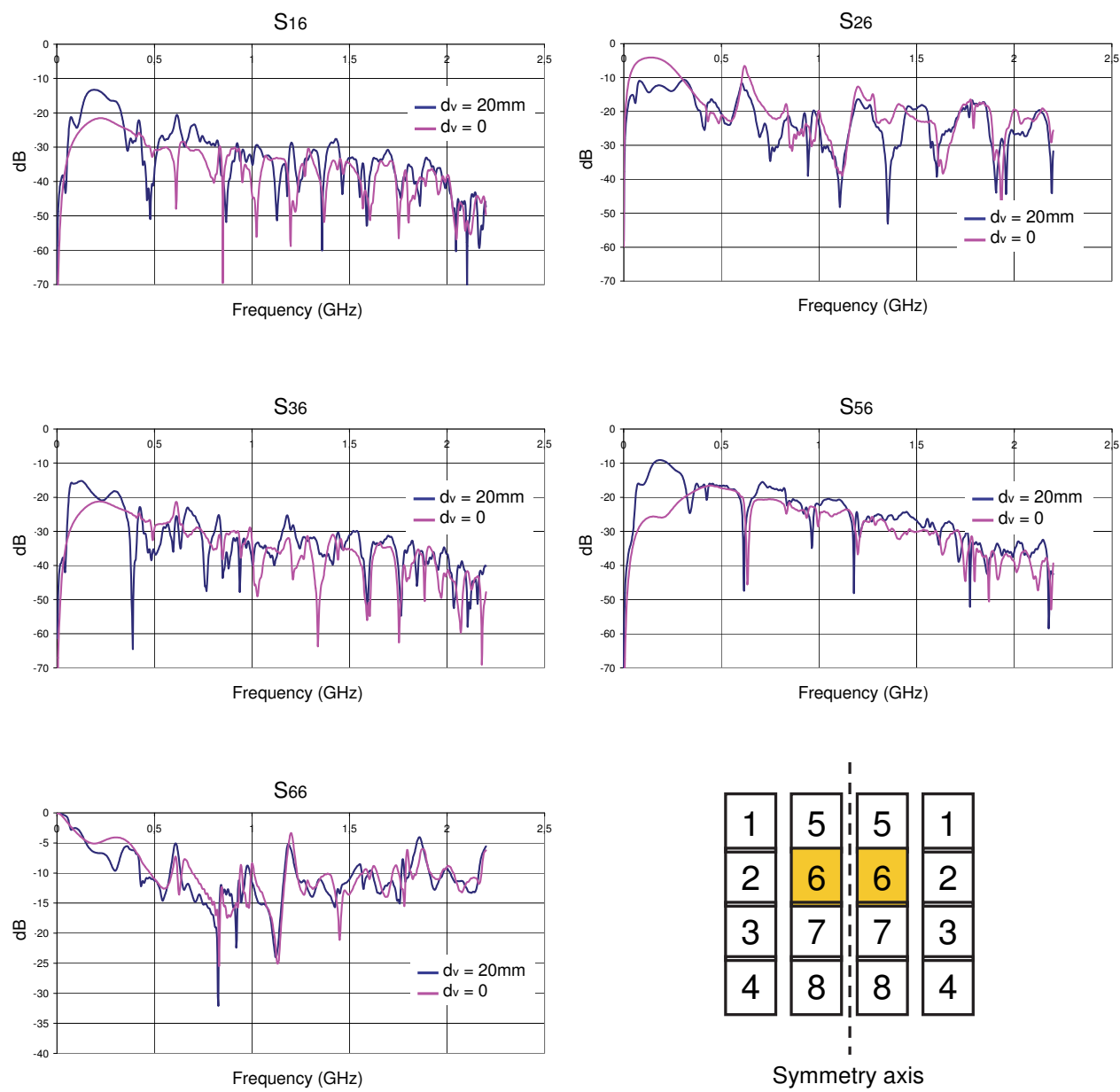

Fig. 23. $S_{\mathrm{ij}}$ coupling parameters 


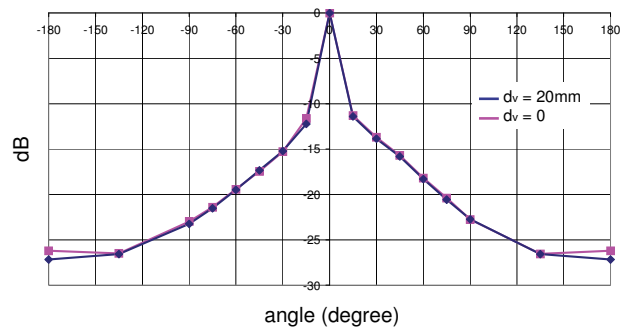

E-plane

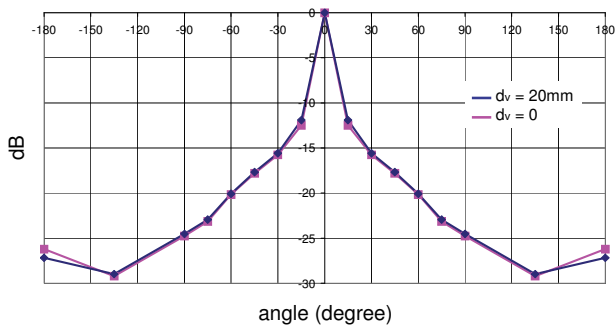

H-plane

Fig. 24. FOM as a function of the incident angle (for $1 \mathrm{~V}$ antenna feed voltage)

The diagrams in Figure 24 representing the amplitude of the radiated field according to the angle of observation are identical from $-135^{\circ}$ to $+135^{\circ}$. As previously recorded, the back radiation is lower when the antennas are in contact. These results confirm the possibility of making an antenna array with all the radiating components in contact.

\subsubsection{Experimental investigation on the array produced}

An initial test was run to verify the operating of each pathway of the array and the summation of the fields in the axis. A reception antenna was placed facing the array. A Picosecond Pulse Labs pulse generator, which enables the generation of a subnanosecond step (level 10V, rise time 150ps, duration 40ns), powered the array through a distributor 1 to 16 . A reception antenna coupled to a singe stroke $20 \mathrm{Gech} / \mathrm{s}$ - $5 \mathrm{GHz}$ oscilloscope ensured the acquisition of the signals transmitted.

The antennas was first placed in a short circuit situation and then activated one after the other, the aim being to verify the increase of the field with the increase in the number of active antennas. It should be noted here that the far field condition was not perfectly respected (distance between the reception and the array in the order of $10 \mathrm{~m}$ ).

Figure 25 shows the evolution of the field (in proportion to the voltage received) according to the number of antennas activated. A mean increase of $20 \mathrm{mV}$ can be seen when an additional antenna is activated. The level recorded for the complete array was $340 \mathrm{mV}$, i.e. approximately 16 times the amplitude of the field radiated by a single antenna. This test therefore enabled an initial validation of the operation of this array. 


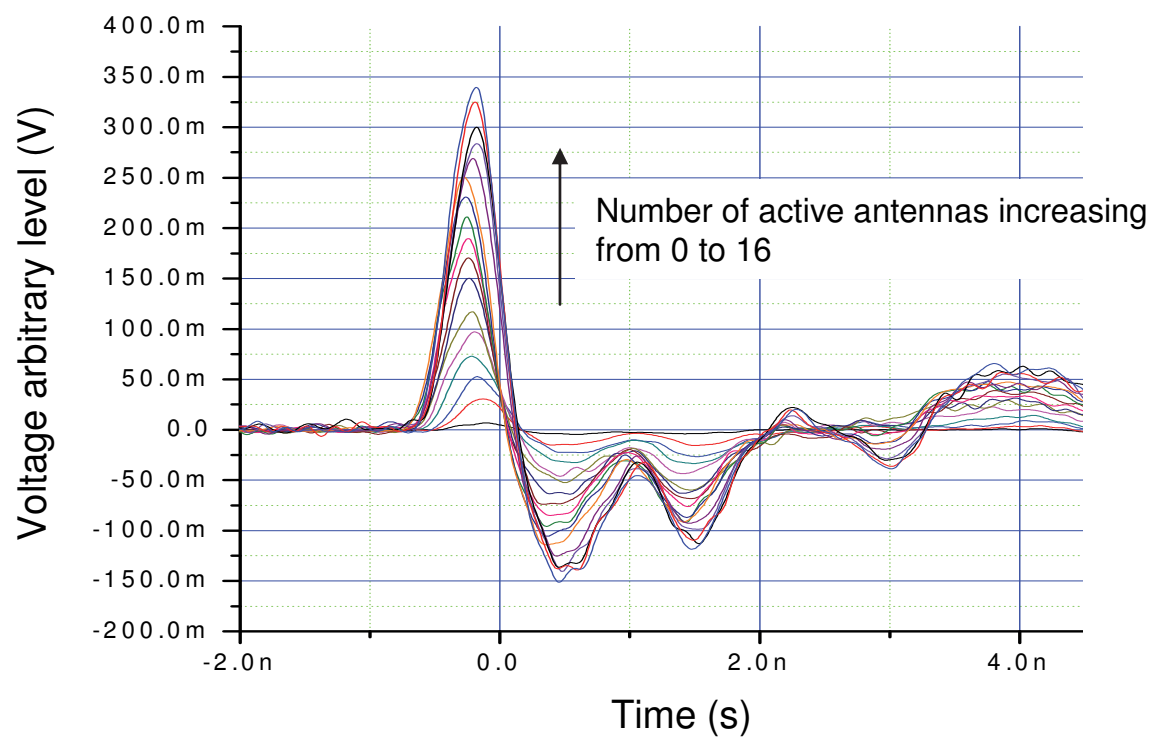

Fig. 25. Experimental field measurement on the array

\subsubsection{Back radiation reducing using quarter wavelength corrugations}

As shown in the previous sections, the back radiation level is under $-25 \mathrm{~dB}$ from $-120^{\circ}$ to $+120^{\circ}$ around the main axis. This back radiation level can be improved by adding quarter wavelength metal corrugations on the array.

Other solutions, such as the use of a metal ground plane, a ferromagnetic absorbent plane or the use of high impedance surfaces, can be implemented to reduce this back radiation. The choice of the solution is essentially dictated by the size, the weight and the ease of use as each of these different techniques offers similar results.

Figure 26 shows the array fitted with its metal corrugations. These rest on a metal plane the dimensions of which are identical to the preceding plate, namely $80 \mathrm{~cm} \times 186 \mathrm{~cm}$. The length $L$ of the corrugations is $50 \mathrm{~cm}$, namely a quarter wave at $150 \mathrm{MHz}$ and the gap $e$ between each metal plate is $7.5 \mathrm{~cm}$.

Corrugations have no effect on the electric field level in the main axis.

The temporal waveform of the electric field back radiated is shown in Figure 27. The array is fed by a bi-exponential pulse with a 200ps rise-time (which matches the frequency spectrum of the array). It is compared to calculated results of the array with no corrugation and the array with only a ground plane mounted just behind antennas. It can be seen that the magnitude of the electric field is greatly reduced and that the temporal form of the field has changed.

Radiation patterns in the $\mathrm{E}$ and $\mathrm{H}$ planes are shown in figure 28. The main radiation lobe remains unchanged and the radiation in the back half space is greatly reduced. The frequencies considered for the radiation patterns are $150 \mathrm{MHz}$ harmonics. That corresponds to the frequencies which are most sensitive to the corrugations. The behavior of the corrugations is similar to that of a simple metal plated for the frequencies far from $150 \mathrm{MHz}$ and the low frequency harmonics. 

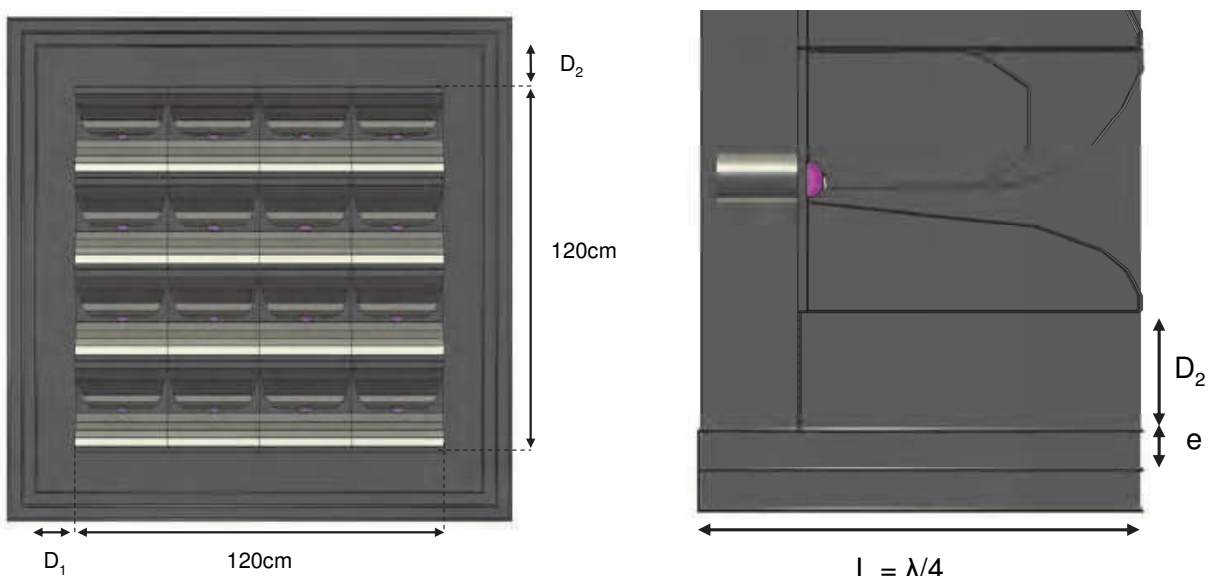

Fig. 26. Design and dimensions of corrugations

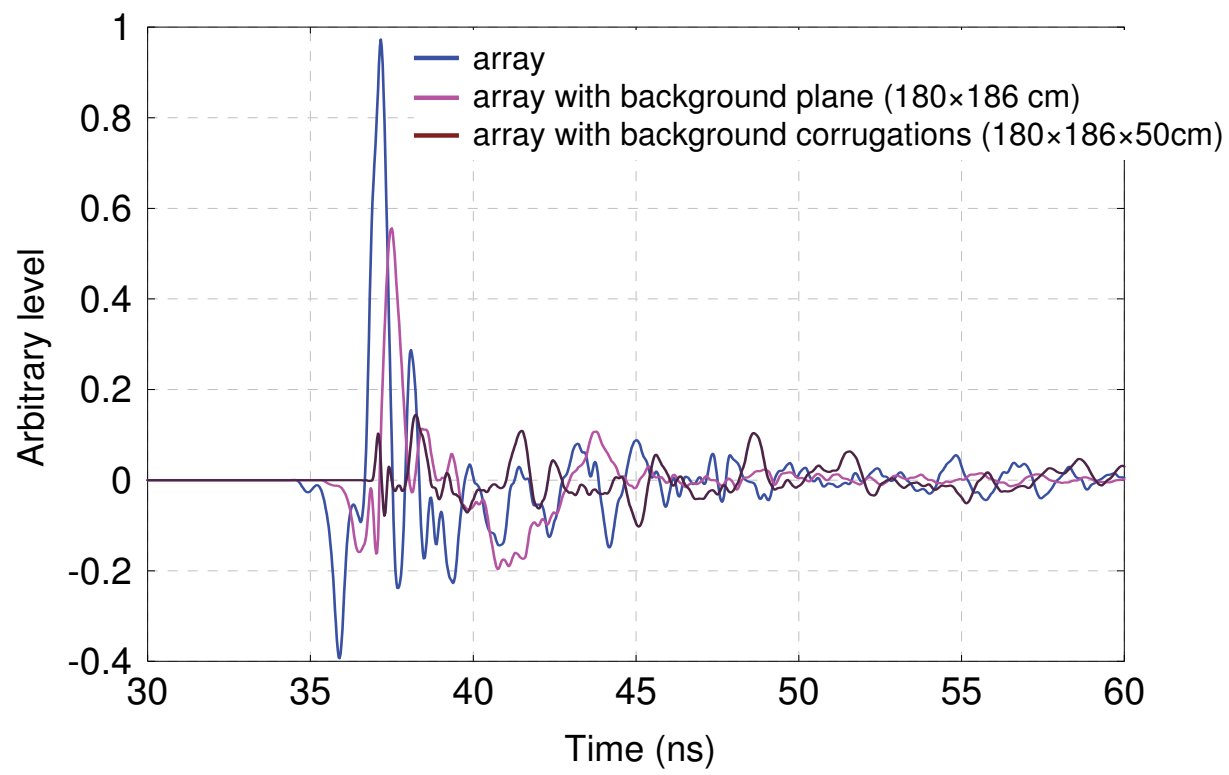

Fig. 27. Back radiation electric field level calculated for an input pulsed voltage (200ps risetime)

However, for the higher frequencies of the spectrum considered $(>1 \mathrm{GHz})$ the input of the corrugations remains undeniable.

In an angle of approximately $90^{\circ}$ around the $180^{\circ}$ angle, the level of back radiation remains under $-30 \mathrm{~dB}$ over the frequency band of $200 \mathrm{MHz}-1 \mathrm{GHz}$ and under $-40 \mathrm{~dB}$ beyond that and around the harmonics of the $150 \mathrm{MHz}$ frequency $(150 \mathrm{MHz}, 300 \mathrm{MHz}, 450 \mathrm{MHz}, 600 \mathrm{MHz}, \ldots$.etc). 
E-plane

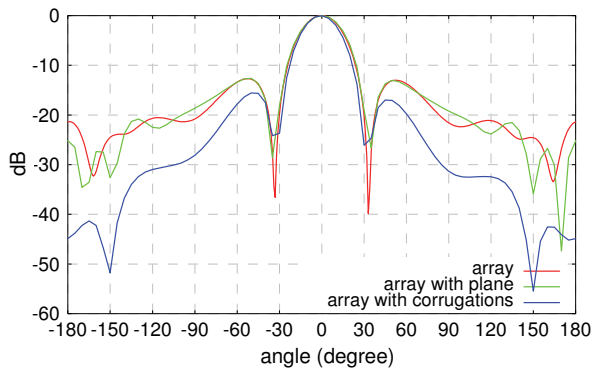

H-plane

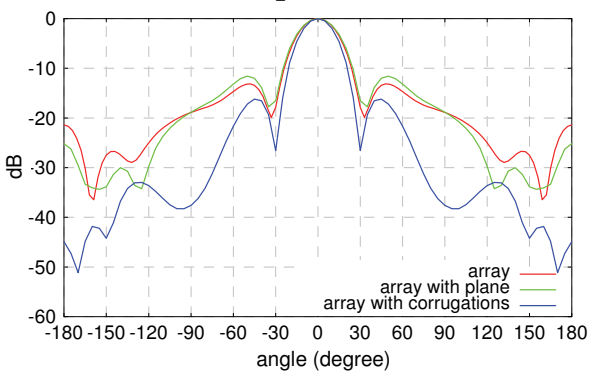

$\mathrm{f}=450 \mathrm{MHz}$
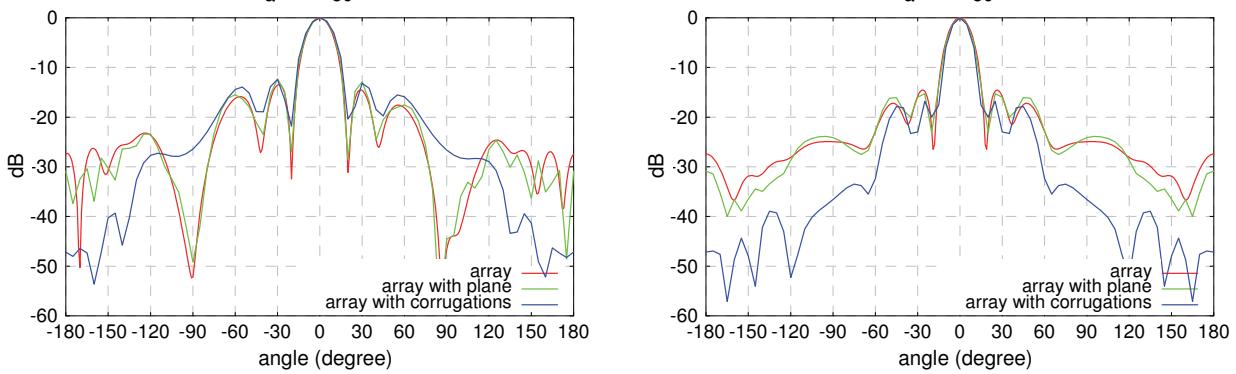

$\mathrm{f}=750 \mathrm{MHz}$
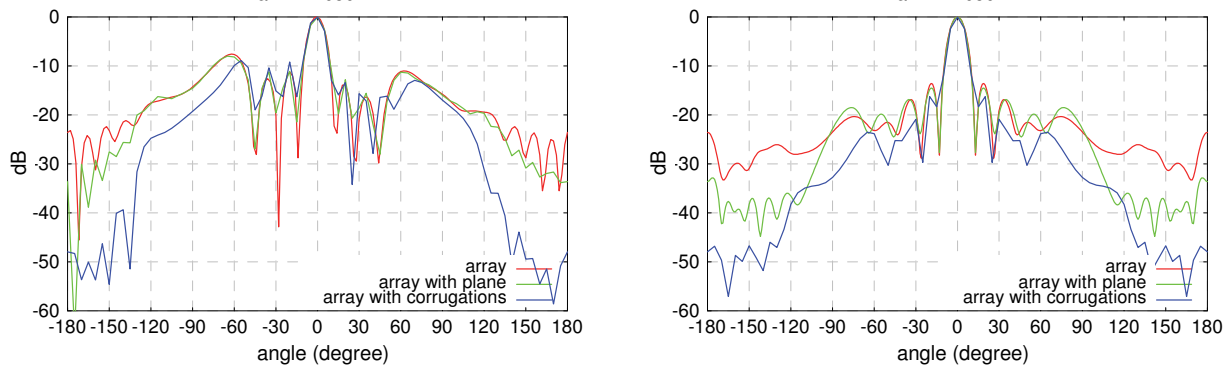

$\mathrm{f}=1050 \mathrm{MHz}$
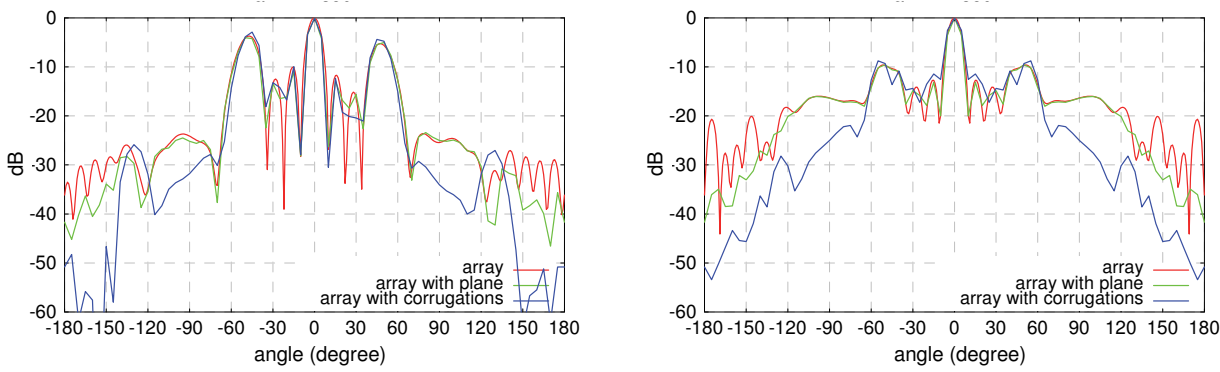

$\mathrm{f}=1350 \mathrm{MHz}$

Fig. 28. Radiation patterns in the $\mathrm{E}$ and $\mathrm{H}$ planes - Benefits of the corrugations 


\section{Conclusion}

The choice and the design of the radiating component of a high power microwave source are vital as they determine the choice of all or part of the complete system.

The choice of antennas available for high voltage ultra wide band applications is relatively limited. It has been shown here that progressive wave antennas behave extremely well in those operational ranges.

Upstream work on the Valentine and $\mathrm{K}$ antennas made it possible to benefit from a definite feedback of experience with those antennas in order to redesign them into new radiating devices specifically adapted to our constraints of compactness. 3D simulations coupled with experimental tests on prototypes made it possible to refine the various geometrical parameters of the components to obtain the best possible levels of electromagnetic performance in small volumes.

The work presented on the Valentine antenna made it possible to validate the concept of deployment of the antenna. It is still a prototype that could be further improved. However, its adaptation at $-10 \mathrm{~dB}$ is between $550 \mathrm{MHz}$ and $3 \mathrm{GHz}$. It is slightly degraded at $-7 \mathrm{~dB}$ between $240 \mathrm{MHz}$ and $550 \mathrm{MHz}$ (probably because of fabrication defects). The gain and factor of merit obtained are in good agreement with the theoretic results. Development of an antenna of this type makes it possible to obtain a compact and lightweight antenna system. More intensive industrialization would make it possible to increase the capacities of this antenna (weight, rapidity of assembly, better observance of the exponential profile, compactness once folded away, etc.).

The theoretic study of the sizing of the $\mathrm{K}$ antenna made it possible to reduce its volume by a factor of 2.3 (antenna dimensions $300 \times 300 \times 385 \mathrm{~mm}$ ). An array of 16 of these antennas offers the best size/performance trade-off. Were this array to be combined with a pulsed source, it would make it possible to obtain a factor of merit of $1 \mathrm{MV}$ for a bi-exponential power signal with a rise time in the order of 200ps and a peak level per antenna of approximately $50 \mathrm{kV}$.

The influence of the distance between the antennas on radiation was studied. All the antennas can be placed in contact both in the horizontal and in the vertical plane. The production of a single block array would however result in the loss of the modular aspect of the system. For example, it is possible to obtain radiation in the two polarizations by arranging half of the antennas in horizontal polarization.

A certain number of solutions to reduce the transient back radiation were also studied. The simplest solution is the combination of a ground plane placed behind the array. This is linked to the plane surface and to the power signal of the antennas (a spectrum covered by the pulse). The addition of quarter wave corrugations is the most effective solution for the field peak level. This method has the disadvantage of offering very high performance at special frequencies but it is not homogenous over the entire spectrum. To lower the radiation further, it would be possible to contemplate longer corrugations. For example, $75 \mathrm{~cm}$ long corrugations would give rise to an initial hole at $150 \mathrm{MHz}$ and then at the higher harmonics and therefore a greater number of holes, but at the expense of size.

\section{Acknowledgments}

This work was sponsored by the French Department of Defense (DGA). 
The authors gratefully acknowledge the excellent technical collaboration of Joël Andrieu, Michèle Lalande and Bernard Jecko from the XLIM Laboratory of Limoges University.

\section{References}

Adler, R.J. (1991). Pulse power formulary, North Star Research Corp.,

Balanis, C. A. (2005), Antenna theory: analysis and design, Third edition by J. Wiley \& Sons, ISBN 0-471-66782-X

Baum, C. E., \& Farr, E. G. (1993). Impulse Radiating Antenna, Ultra-wideband, Short Pulse Electromagnetic, ed. Bertoni, New York, Plenum, pp. 139-147, available from http: \\www.farr-research.com

Bigelow, W. S., Farr, E. G., Bowen, L. H., Ellibee, D. E., \& Lawry, D. I., (2004). Design and Characterization of lens TEM Horn, Sensor and Simulation Notes, Note 490, available from http: \\www.farr-research.com

Cadilhon, B., Pécastaing, L., Reess, T., Silvestre De Ferron, A., Pignolet, P., Vauchamp, S., Andrieu, J., \& Lalande M., (2010). High Pulsed Power Sources for Broadband Radiation, IEEE Transactions on Plasma Science, Vol. 38, n 10, pp. 2593-2601, ISSN: 0093-3813

Delmote, P., Dubois, C., Andrieu, J., Lalande, M., Bertrand, V., Beillard, B., Jecko, B., Largeau, T., Guillerey, R., \& Colson S., (2004). Two original UWB antennas: the Dragonfly antenna and the Valentine antenna, Proceedings of Radar 2004 Symposium, Toulouse

Diot, J.C., (2006). Design and realization of an impulse optoelectronic Ultra Wide Band radar, $\mathrm{Ph}$. D. dissertation, University of Limoges, $\mathrm{n}^{\circ} 502006$

Diot, J.C., Delmote, P., Andrieu, J., Lalande, M., Bertrand, V., Jecko, B., Colson, S., Guillerey, R., \& Brishoual, M., (2007). A novel antenna for transient applications in the frequency band $300 \mathrm{MHz}-3 \mathrm{GHz}$ : the Valentine antenna, IEEE Transactions on Antennas and Propagation, vol. 55, n³, pp 987-990, ISSN: 0018-926X

Efremov, A. M., Koshelev, V. I., Kovalshuk, B. M., Plisko, V. V., \& Sukhushin, K. N., (2006). High-power sources of ultrawideband radiation with subnanosecond pulse length, Proceedings of the 2nd International Congress on radiation physics, high current electronics and modification of materials, pp. 446-449, Tomsk

Farr, E.G., Sower, G.D., \& Buchenauer C. J., (1994). Design considerations for ultrawideband, high-voltage baluns, Sensor and Simulations Notes, $\mathrm{n}^{\circ} 371$, available from http: \\www.farr-research.com

Farr, E. G., Bowen, L. H., Lawry, D. I., \& Tyo J. S., (2004). An ultra compact impulse radiating antenna, Sensor and Simulation Notes, $\mathrm{n}^{\circ} 494$, available from http: \\www.farr-research.com

Foster, P.R., \& Tun, S.M., (1995). A wideband balun from coaxial line to TEM line, Proceedings of the IET Conference on Antennas and Propagation, pp. 286-290, Eindhoven, ISBN: 0-85296-637-7

Koshelev, V. I., Buyanov, Y. I., Andreev, Y. A., Plisko, V. V., \& Sukhushin K. N., (2001). Ultrawideband radiators of high-power pulses, Proceedings of the IEEE Pulsed Power Conference, Vol. 2, pp. 1661-1667, Tomsk, ISBN: 0-7803-7120-8

Koshelev, V. I., Gubanov, V. P., Efremov, A. M., Korovin, S. D., Kovalshuk, B. M., Plisko, V. V., Stepchenko, A. S., \& Sukhushin K. N., (2006). High-power ultrawideband radiation source with multielement array antenna, Proceedings of the 2 nd 
International Congress on radiation physics, high current electronics and modification of materials, pp. 258-261, Tomsk

Malik, N.H., Al-Arainy, A.A., \& Qureshi, M.I., (1998). Electrical insulation in power systems, In: Power engineering, H. Lee Willis, (Ed.):, Marcel Dekker Inc., ISBN: 0-8247-0106-2

Pécastaing, L., Cadilhon, B., Reess, T., Silvestre De Ferron, A., Pignolet, P., Vauchamp, S., Andrieu, J., Lalande M., \& Brasile J.P., (2009). A 250kV, 300ps, 350Hz Marx generator as source for an UWB radiation system, Proceedings of the IEEE Pulsed Power Conference, Washington, p. 51-56, ISBN: 978-1-4244-4064-1 


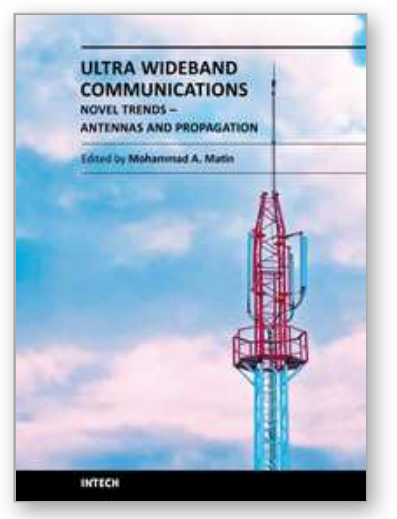

\section{Ultra Wideband Communications: Novel Trends - Antennas and Propagation}

Edited by Dr. Mohammad Matin

ISBN 978-953-307-452-8

Hard cover, 384 pages

Publisher InTech

Published online 09, August, 2011

Published in print edition August, 2011

This book explores both the state-of-the-art and the latest achievements in UWB antennas and propagation. It has taken a theoretical and experimental approach to some extent, which is more useful to the reader. The book highlights the unique design issues which put the reader in good pace to be able to understand more advanced research.

\section{How to reference}

In order to correctly reference this scholarly work, feel free to copy and paste the following:

Baptiste Cadilhon, Bruno Cassany, Patrick Modin, Jean-Christophe Diot, Valérie Bertrand and Laurent Pécastaing (2011). Ultra Wideband Antennas for High Pulsed Power Applications, Ultra Wideband Communications: Novel Trends - Antennas and Propagation, Dr. Mohammad Matin (Ed.), ISBN: 978-953-307452-8, InTech, Available from: http://www.intechopen.com/books/ultra-wideband-communications-noveltrends-antennas-and-propagation/ultra-wideband-antennas-for-high-pulsed-power-applications

\section{INTECH}

open science | open minds

\section{InTech Europe}

University Campus STeP Ri

Slavka Krautzeka 83/A

51000 Rijeka, Croatia

Phone: +385 (51) 770447

Fax: +385 (51) 686166

www.intechopen.com

\section{InTech China}

Unit 405, Office Block, Hotel Equatorial Shanghai

No.65, Yan An Road (West), Shanghai, 200040, China

中国上海市延安西路65号上海国际贵都大饭店办公楼 405 单元

Phone: +86-21-62489820

Fax: $+86-21-62489821$ 
(C) 2011 The Author(s). Licensee IntechOpen. This chapter is distributed under the terms of the Creative Commons Attribution-NonCommercialShareAlike-3.0 License, which permits use, distribution and reproduction for non-commercial purposes, provided the original is properly cited and derivative works building on this content are distributed under the same license. 